\title{
Enhanced Kalman Filter Navigation Algorithm Based on Correntropy and Fixed-Point Update
}

\author{
Sirish Kumar Pagoti ${ }^{1, *}$, Bala Sai Srilatha Indira Dutt Vemuri ${ }^{2}$, Mohammad Khaja Mohiddin $^{3}$ \\ ${ }^{1}$ Department of Electronics and Communication Engineering, Aditya Institute of Technology and Management, Tekkali, \\ Andhra Pradesh, India \\ ${ }^{2}$ Gandhi Institute of Technology and Management (Deemed to be University), Visakhapatnam, Andhra Pradesh, India \\ ${ }^{3}$ Bhilai Institute of Technology, Raipur, Chhattisgarh, India \\ Received 11 July 2021; received in revised form 17 October 2021; accepted 18 October 2021 \\ DOI: https://doi.org/10.46604/ijeti.2022.8072
}

\begin{abstract}
The accuracy of position estimation plays a key role in many of the precise positioning applications such as category I (CAT-I) aircraft landings, survey work, etc. To improve the accuracy of position estimation, a novel kinematic positioning algorithm designated as correntropy Kalman filter (CKF) is proposed in this study. Instead of minimum mean square error (MMSE), correntropy criterion (CC) is used as the optimality criterion of CKF. The prior estimates of the state and covariance matrix are computed in CKF and a novel fixed-point algorithm is then used to update the posterior estimates. The data of a dual-frequency global positioning system (GPS) receiver located at Indian Institute of Science (IISc), Bangalore $\left(13.021^{\circ} \mathrm{N} / 77.5^{\circ} \mathrm{E}\right)$ is collected from Scripps Orbit and Permanent Array Centre (SOPAC) to implement the proposed algorithm. The results of the proposed CKF algorithm are promising and exhibit significant improvement in position estimation compared to the conventional methods.
\end{abstract}

Keywords: correntropy criterion (CC), correntropy Kalman filter (CKF), fixed-point algorithm, global positioning system (GPS), minimum mean square error (MMSE)

\section{Introduction}

Precise navigation, positioning, and strong surveillance systems are essential for the safeguard of the countries which are located in low latitude regions, e.g. India. This has led to the development and evolution of numerous such systems. Some of these system's real-world applications include aviation, marine, mining, military, medicine, and agriculture. These systems can be segregated into two categories depending on the nature of operation and the origin of the coordinate system. They are (i) source localization system and (ii) global positioning system (GPS).

Source localization system is a relative positioning system used to find an unknown radiating source (e.g., radar) close to a fixed point. Some examples of source localization systems are radar tracking, mobile unit tracking, and unmanned ariel vehicle (UAV) tracking system. On the other hand, GPS allows each receiving unit/object (e.g., ship, aircraft, and handheld navigator) to find its position anywhere globally. Contrary to source localization system, GPS considers the earth's center to be the origin of the positioning coordinate system. It uses the range of information obtained from the known location of the radiating sources or spacecrafts to find the user/object position.

The accuracy of source localization system and GPS is affected by several factors such as measurement techniques, environmental effects on measurement, positioning solutions, etc. Among these factors, identifying an optimal measurement technique is considered significant because an improper measurement technique provides a diverging solution. For instance, a

* Corresponding author. E-mail address: sirishdg@ gmail.com

Tel.: +91-9866212171 
measurement technique that provides good results for a positioning application with air as a medium may not show the same performance in the underwater environment [1]. Similarly, a measurement technique that provides reasonable estimates with a set of geographic conditions does not guarantee the same performance with other geographic conditions. Significantly, the geographic region of India having North latitude between $8^{\circ} 4^{\prime}$ and $37^{\circ} 6^{\prime}$ and East longitude between $68^{\circ} 7^{\prime}$ and $97^{\circ} 25^{\prime}$ is highly subjected to atmospheric effects like ionosphere and low satellite visibility when compared to the mid-latitude countries. This is the primary cause of the reduced accuracy in GPS performance over the Indian subcontinent.

Hence, identifying an optimal measurement technique for precise source localization and GPS applications is highly essential. With the advent of GPS, navigation has been transformable, particularly in the area of civil aviation. The satellite-based systems of navigation offer higher accuracy compared to traditional navigational aids, e.g., very-high-frequency omnidirectional range (VOR), distance measuring equipment (DME), and instrument landing system (ILS). The positional accuracy readings are influenced by many factors of error, such as ionosphere or troposphere related delay, a bias of satellite clock, a proper receiving unit, multiple paths of propagation as well as receiver/object geometry concerning satellites.

Due to these discrepancies, the standalone GPS does not satisfy the aircraft landing stipulations, such as category I (CAT-I) aircraft landings. Precision approaches in which the desirable horizontal accuracy and vertical accuracy are $16 \mathrm{~m}$ and 4.5-7 m, respectively [2-3]. There is an imperative need for the improvement of the GPS performance; this is done by augmentation, i.e., space-based augmentation systems (SBASs). All the SBASs require satisfying the enroute navigation accuracy (2.2 nmi accuracy and $2 \mathrm{~min}$ integrity) and vertical guidance (220 m horizontal accuracy, $20 \mathrm{~m}$ vertical accuracy, and $10 \mathrm{sec}$ integrity) [3]. Nevertheless, the predominant factor over the usage of appropriate ionospheric model and satellite configuration is the receiver position estimation algorithm like Kalman filter (KF), which is not accessible in the public domain because of the trade-related and secrecy-oriented justification.

The investigations carried out on finding the optimal measurement technique for source localization systems are useful for precise position estimation of an unknown radiating source, mobile phone localization using base station signals, indoor positioning in mines, buildings, etc. According to the information from International Civil Aviation Organization (ICAO), the currently used primary navigation systems for air traffic control were replaced by GPS-based navigation systems in the year 2017.

The objective of this study is to propose a strengthened global navigation satellite system (GNSS)/GPS-based navigation system. The proposed algorithm (correntropy Kalman filter (CKF)) is useful for navigation and surveying in urban canyons and dense forest areas where the satellite visibility is low. CKF is developed based on the correntropy criterion (CC) and a fixed-point algorithm for minimum variance in position estimation that suits safety-critical applications like CAT-I aircraft landings over the low latitude Indian subcontinent. Finally, the proposed navigation algorithm is validated with the real-time data collected from the dual-frequency GPS receiver located at Indian Institute of Science (IISc), Bangalore $\left(13.021^{\circ} \mathrm{N} / 77.5^{\circ} \mathrm{E}\right)$, India.

The organization of the study is as follows. The corresponding related works are presented in section 2. Section 3 shows the details related to the correntropy notation, the difference between minimum mean square error (MMSE) and correntropy, and the fixed-point algorithm for the estimation of correntropy. Section 4 covers the development of CKF for GPS-aided GEO augmented navigation (GAGAN) based CAT-I aircraft landing requirements. In section 5, the performance and error analysis is carried out through simulation results. The overall conclusions are provided in section 6 .

\section{Literature Review}

The basic premises and system details of positioning systems (i.e., source localization system and GPS), measurement techniques, GPS signal structure, GPS observables, and the iterative and recursive navigational techniques covering linear algebra are essential. The adaptive KF algorithm is a series of recursively optimized estimates for the use of time-domain information with relatively lower computational complexity to minimize device errors. It is a crucial tool with full navigation and positioning applications by eliminating errors in the least square model. The demerit is that accurate statistical information 
is needed, without which less precise and divergent information will occur. To overcome this deficiency, Xiong et al. [4] have proposed a new and robust GPS algorithm based on dead reckoning and a powerful strong tracking filter (STF). The adaptive fading factor is used to change the gain matrix in real-time, preserving the orthogonality concept that ensures that all useful information is extracted from the remaining content.

Besides, residual covariance ( $\mathrm{RC}$ ) is specified to evaluate the filter algorithm's output and the closed-form relation of RC in KF in the event of an inaccurate system model. In all three cases (i.e., inaccurate system model, erroneous initial value, and abrupt change of states), it has been demonstrated that the RC of KF has a bias compared to the desired values to not adhere to the orthogonality principle (OP) resulting in insufficient tracking power. On the contrary, the RC of STF conforms to the RC of OP because the fading factor in the proposed technique produces higher tracking efficiency. It is proved by simulation that the GPS with STF outstrips the traditional KF algorithm [5].

Owing to some gradient based adaptive filtering algorithms' efficiency against the measurement noise from erroneous sources, the measurement noise has a heavy-tailed distribution, and the KF's performance suffers as a result in real-world situations. Many filtering techniques, such as Student's t-based KF [6-7], have been proposed to increase the estimation accuracy of the linear system with heavy-tailed measurement noise. Finally, the robust KF like Student's t-based KF has better robustness but slightly higher computational complexity than the existing state-of-the-art methods.

Santra et al. [8] have checked the exact approach for satellite navigation. The accuracy parameters for the latitude, longitude, and altitude position solution are specified using Indian regional navigation satellite system (IRNSS/NavIC) dual-frequency (L5+S) data. Quality measurement should be carried out in geodetic coordinates for a position solution. Rajasekhar et al. [9] have investigated the most suitable geometry of the receiver for improving the accuracy of positioning utilizing the GPS of IRNSS combined constellation over the Hyderabad region at any time and in all weather conditions for finding the precise location of the receiver. Typically, positioning accuracy is reduced by the satellite geometry, receiver dimensions, and the error related to atmosphere and multi-path propagation. Dilution of precision (DOP) is a parameter of the satellite receiver's geometrical dimension. The proposed method utilizes DOP's relationship with a combined constellation of GPS and IRNSS to have greater positioning accuracy required for CAT-I aircraft landings, survey work, and disaster management. Hatano et al. [10] have proposed a useful positioning method with two GNSS satellites in urban areas such that the estimates of their position can be obtained with the least number of satellites. This method eliminates the problem by causing multi-path or non-line-of-sight (NLOS). Ribeiro [11] has discussed KF and extended Kalman filter (EKF) thoroughly. In general filtering, it is observed that in linear and Gaussian scenarios, the standard filter matches with KF, which is suitable for estimating the state to minimize the error. KF is evaluated by comparing the raw data and a simple moving average filter. According to the results, KF reduces the variance in comparison with the raw data [12].

Luo et al. [13] have proposed a method based on EKF for UAV position estimation and collision avoidance in outdoor search scenarios by utilizing the received signal strength from an onboard module of communication. Shokri et al. [14] have proposed a unique, fast, and accurate GPS positioning technique employing a weighted Kalman filter (WKF) that supported the variance estimation approach. Hao et al. [15] have proposed a modified EKF algorithm with delayed update (DU-EKF) for speeding up the convergence rate without the receiver's approximate initial position as required on normal EKF. This method, additionally, improves the accuracy of positioning and velocity measurement.

Jwo et al. [16] have analyzed the linearized KF and EKF, and have given critical remarks with geodetic navigation examples. Ge et al. [17] have analyzed the difference between the extended strong tracking filter (ESTF) and EKF in the content of carrier tracking estimation. Zhang et al. [18] have proposed a hybrid algorithm based on multiple-decrease factor (MDF) cubature Kalman filter and random forest (RF) for GPS/inertial navigation system (INS) during GPS outages. Their proposed filter guarantees the restricted filter divergence and increases the robustness. 
Zhang et al. [19] have proposed a novel adaptive filter based on a nonlinear cubature Kalman filter and an estimate of variance-covariance components (VCE). Cubature Kalman filter was used to solve nonlinearity, but VCE was used for the nonlinear system's real-time estimation noise correlation matrix. Liu et al. [20] have proposed a novel Kalman filter based on maximum correntropy criterion (MCC) called maximum correntropy Kalman filter (MCKF). The optimality condition is decided by MCC instead of the traditional MMSE used in the regular KF suitable for Gaussian assumptions.

Literature survey unveils that to increase demand for an accurate positioning system, optimal measurement strategies and precise navigation solutions are necessary. For critical GPS applications like CAT-I aircraft landings, low variance in estimation is crucial besides the estimated position accuracy. Moreover, the number of onboard system parameters and dynamics needs to be analyzed while estimating the position.

\section{Correntropy Kalman Filter (CKF)}

\subsection{Correntropy notation}

As discussed earlier, the correntropy of two random variables "A" and "B" is given by Eq. (1) [21]:

$$
\mathrm{V}(\mathrm{A}, \mathrm{B})=\mathrm{E}\left[\mathrm{k}_{\mathrm{e}}(\mathrm{A}, \mathrm{B})\right]=\int \mathrm{k}_{\mathrm{e}}(\mathrm{a}, \mathrm{b}) \mathrm{d} \mathrm{J}_{\mathrm{f}_{\mathrm{AB}}}(\mathrm{a}, \mathrm{b})
$$

where "E" is the expectation vector, and $\mathrm{k}_{\mathrm{e}}($,$) is the shift-invariant Mercer kernel. In this research work, unless specified$ differently, the kernel function is the Gaussian function given by:

$$
\mathrm{k}_{\mathrm{e}}(\mathrm{a}, \mathrm{b})=\mathrm{G}_{\Omega}(\mathrm{e})=\exp \left(-\frac{\mathrm{e}^{2}}{2 \Omega^{2}}\right)
$$

where $\mathrm{e}=\mathrm{a}-\mathrm{b}$ and $\Omega>0$. The kernel bandwidth has a positive value. In practical application, the number of data is limited and the joint distribution $\mathrm{J}_{\mathrm{f}_{\mathrm{AB}}}$ is ordinarily unknown. In such cases, the correntropy can be estimated by a sample mean estimator:

$$
\hat{\mathrm{V}}(\mathrm{A}, \mathrm{B})=\frac{1}{\mathrm{~L}} \sum_{\mathrm{i}=1}^{\mathrm{L}} \mathrm{G}_{\Omega}[\mathrm{e}(\mathrm{i})]
$$

where $\mathrm{e}(\mathrm{i})=\mathrm{a}(\mathrm{i})-\mathrm{b}(\mathrm{i})$ with $\mathrm{a}(\mathrm{i}), \mathrm{b}(\mathrm{i})\}_{\mathrm{i}=1}^{\mathrm{L}}$ yielding $\mathrm{L}$ samples is taken from $\mathrm{J}_{\mathrm{fB}}$. The Taylor series expansion of the Gaussian kernel is given by:

$$
\mathrm{V}(\mathrm{A}, \mathrm{B})=\sum_{1=0}^{\infty} \frac{(-1)^{1}}{2^{1} \sigma^{21} 1 !} \mathrm{E}\left[(\mathrm{A}-\mathrm{B})^{21}\right]
$$

As shown, the correntropy is a weighted sum of the random variable's (A-B) even-order moments. The kernel bandwidth is a weighting parameter for second- and higher-order moments. The correntropy is dominated by second-order moments when $\Omega$ is much greater than the dynamic range results [22].

\subsection{Comparison between MMSE and correntropy}

If " $\mathrm{A}$ " and " $\mathrm{B}$ " are two random variables and $\mathrm{E}=\mathrm{B}-\mathrm{A}$, then $\operatorname{MSE}(\mathrm{A}, \mathrm{B})$ is defined as $\mathrm{a}=\mathrm{b}$ [23]:

$$
\operatorname{MSE}(\mathrm{A}, \mathrm{B})=\mathrm{E}\left[(\mathrm{A}-\mathrm{B})^{2}\right]=\iint_{\mathrm{a}, \mathrm{b}}(\mathrm{a}-\mathrm{b})^{2}=\int_{\mathrm{e}} \mathrm{e}^{2} \mathrm{~J}_{\mathrm{f}_{\mathrm{E}}}(\mathrm{e}) \mathrm{de}
$$


whereas

$$
V(A, B)=E[k(A-B)]=\iint_{a, b} k(a-b) f_{A B}(a, b) d a d b=\int_{e} k(e) J_{f_{E}}(e) d e
$$

It may be noted that MMSE is quadratic for the joint space having a valley accompanying the line $\mathrm{a}=\mathrm{b}$. The similarity measures show how distinctive "A" is from " $\mathrm{B}$ " in terms of possibility; the intuitive explanation is that MMSE is also a similarity measure on the joint space. The improvement in values on the $\mathrm{a}=\mathrm{b}$ line corresponds to an improved contribution of the samples well removed from the typical error distribution.

\subsection{Fixed-point solution for correntropy estimation}

For the regression in linear adaptive filtering, an optimal weight vector under CC is that one could maximize [24]:

$$
\mathrm{M}_{\mathrm{C}}=\mathrm{E}\left\{\mathrm{G}_{\Omega}[\mathrm{e}(\mathrm{i})]\right\}
$$

where the error is $e(i)=y(i)-b(i)=y(i)-W^{T} A(i)$. Here, the value at a time is $i$, the output of filter is $b(i)=W^{\mathrm{T}} A(i)$, the weight vector is $W=\left(w_{1}, w_{2}, \ldots w_{m}\right)^{T}$, and the input vector is $A(i)=\left[a_{1}(i), a_{2}(i), \ldots a_{m}(i)\right]^{T}$.

\subsection{Derivation of the proposed algorithm}

The conventional KF deteriorates the performance in non-Gaussian noises, particularly for the system distributed by impulsive noises [25-27]. As discussed above, KF is formed on the MMSE criterion, which is the leading cause of the problem [20]. It collects only second-order error statistics and becomes susceptible to large outliers. Using CC and CKF is derived to solve it. CKF works best in non-Gaussian environments as correntropy has second- and higher-order error moments [28-29]. The CKF algorithm's computational flow chart is presented in Fig. 1.

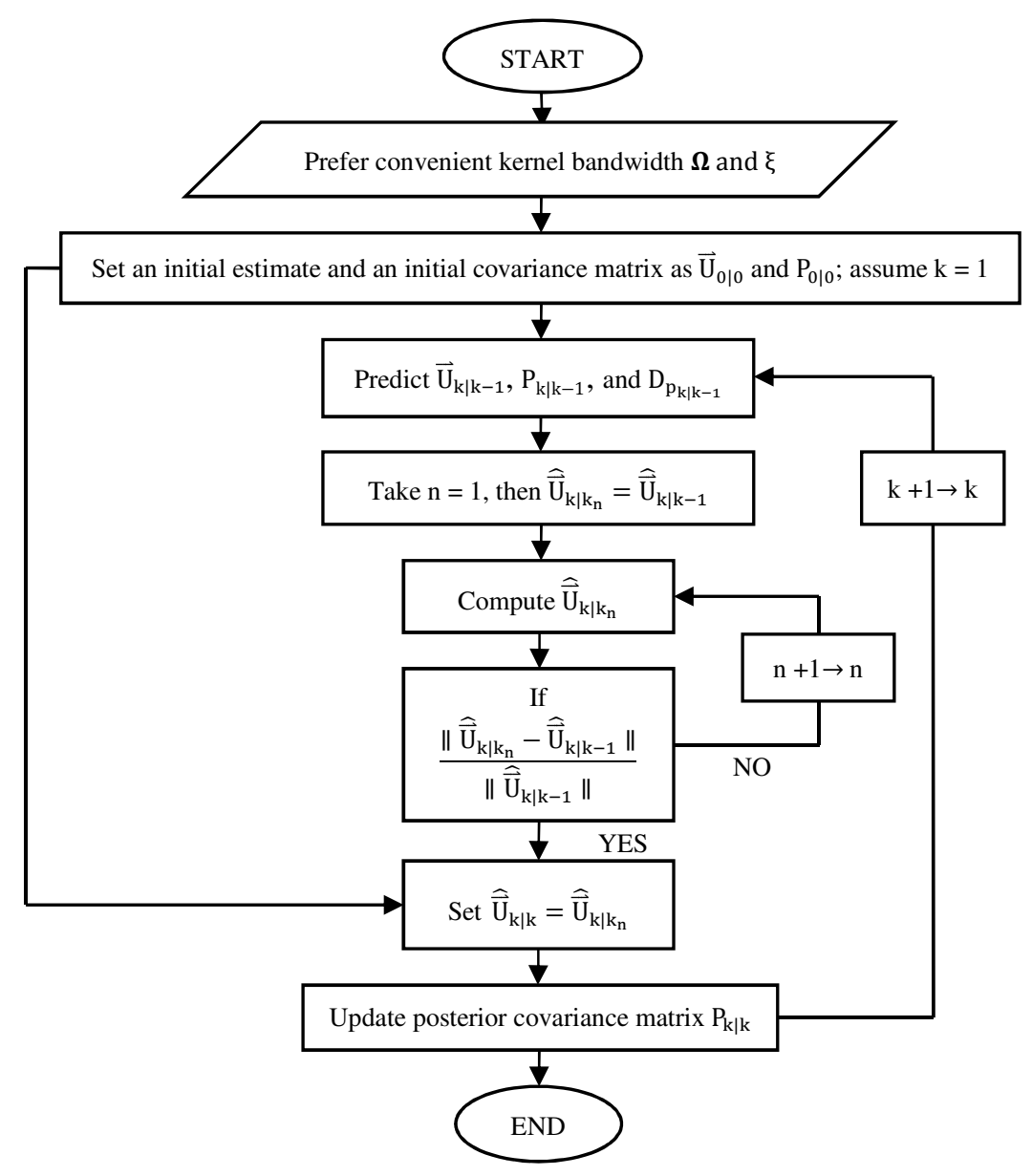

Fig. 1 Computational flow chart of CKF 
Consider a linear system described by the following state and measurement equations:

$$
\begin{aligned}
& \overrightarrow{\mathrm{U}}_{\mathrm{k}}=\Phi_{\mathrm{k}-1} \overrightarrow{\mathrm{U}}_{\mathrm{k}-1}+\mathrm{q}_{\mathrm{k}-1} \\
& \overrightarrow{\mathrm{z}}_{\mathrm{k}}=\mathrm{H}_{\mathrm{k}} \overrightarrow{\mathrm{U}}_{\mathrm{k}}+\mathrm{r}_{\mathrm{k}}
\end{aligned}
$$

where $\vec{U}_{k}$ is the n-dimensional state vector, and $\vec{z}_{k}$ is the m-dimensional measurement vector for instant " $k$ ". $\Phi$ is the system matrix, $\mathrm{H}$ is the observation matrix, $\mathrm{q}_{\mathrm{k}-1}$ is the mutually uncorrelated process noise, and $\mathrm{r}_{\mathrm{k}}$ is the measurement noise.

$$
\begin{aligned}
& E\left(q_{k-1} q_{k-1}^{T}\right)=Q_{k-1} \\
& E\left(r_{k} r_{k}^{T}\right)=R_{k}
\end{aligned}
$$

KF has two steps in general: predict and update.

(1) Predict: The prior mean and covariance matrices are given by:

$$
\begin{aligned}
& \overrightarrow{\mathrm{U}}_{\mathrm{k} \mid \mathrm{k}-1}=\Phi_{\mathrm{k}-1} \overrightarrow{\mathrm{U}}_{\mathrm{k}-1 \mid \mathrm{k}-1} \\
& \mathrm{P}_{\mathrm{k} \mid \mathrm{k}-1}=\Phi_{\mathrm{k}-1} \mathrm{P}_{\mathrm{k}-1 \mid \mathrm{k}-1} \Phi_{\mathrm{k}-1}^{\mathrm{T}}+\mathrm{Q}_{\mathrm{k}-1}
\end{aligned}
$$

(2) Update: The gain of KF is computed as:

$$
\mathrm{K}_{\mathrm{k}}=\mathrm{P}_{\mathrm{k} \mid \mathrm{k}-1} \mathrm{H}_{\mathrm{k}}^{\mathrm{T}}\left(\mathrm{H}_{\mathrm{k}} \mathrm{P}_{\mathrm{k} \mid \mathrm{k}-1} \mathrm{H}_{\mathrm{k}}^{\mathrm{T}}+\mathrm{R}_{\mathrm{k}}\right)^{-1}
$$

It is observed that the posterior state is the prior state coupled with innovation weighted by the KF gain:

$$
\overrightarrow{\mathrm{U}}_{\mathrm{k} \mid \mathrm{k}}=\overrightarrow{\mathrm{U}}_{\mathrm{k} \mid \mathrm{k}-1}+\mathrm{K}_{\mathrm{k}}\left(\overrightarrow{\mathrm{z}}_{\mathrm{k}}-\mathrm{H}_{\mathrm{k}} \overrightarrow{\mathrm{U}}_{\mathrm{k} \mid \mathrm{k}-1}\right)
$$

Furthermore, the posterior covariance is updated recursively:

$$
\mathrm{P}_{\mathrm{k} \mid \mathrm{k}}=\left(\mathrm{I}-\mathrm{K}_{\mathrm{k}} \mathrm{H}_{\mathrm{k}}\right) \mathrm{P}_{\mathrm{k} \mid \mathrm{k}-1}\left(\mathrm{I}-\mathrm{K}_{\mathrm{k}} \mathrm{H}_{\mathrm{k}}\right)^{\mathrm{T}}+\mathrm{K}_{\mathrm{k}} \mathrm{R}_{\mathrm{k}} \mathrm{K}_{\mathrm{k}}^{\mathrm{T}}
$$

The linear model depicted in the above equation gives:

$$
\left[\begin{array}{c}
\hat{\overrightarrow{\mathrm{U}}}_{\mathrm{k} \mid \mathrm{k}-1} \\
\overrightarrow{\mathrm{Z}}_{\mathrm{k}}
\end{array}\right]=\left[\begin{array}{r}
\mathrm{I} \\
\mathrm{H}_{\mathrm{k}}
\end{array}\right] \overrightarrow{\mathrm{U}}_{\mathrm{k}}+\mathrm{c}_{\mathrm{k}}
$$

where $\mathrm{I}$ is a $\mathrm{n} \times \mathrm{n}$ identity matrix, and $\mathrm{c}_{\mathrm{k}}$ is:

$$
\mathrm{c}_{\mathrm{k}}=\left[\begin{array}{c}
-\left(\overrightarrow{\mathrm{U}}_{\mathrm{k}}-\overrightarrow{\mathrm{U}}_{\mathrm{k} \mid \mathrm{k}-1}\right) \\
\mathrm{r}_{\mathrm{k}}
\end{array}\right]
$$

with

$$
E\left(c_{k} c_{k}^{T}\right)=\left[\begin{array}{cc}
P_{k \mid k-1} & 0 \\
0 & R_{k}
\end{array}\right]=\left[\begin{array}{cc}
D_{p_{k \mid k-1}} D_{p_{k \mid k-1}^{T}}^{T} & 0 \\
0 & D_{r_{k}} D_{r_{k}}^{T}
\end{array}\right]=D_{k} D_{k}^{T}
$$


Here, $D_{k}$ may be available through Cholesky decomposition of $E\left[c_{k} c_{k}^{T}\right]$. The multiplication of both sides of Eq. (17) by $D_{k}^{-1}$ is:

$$
\mathrm{Y}_{\mathrm{k}}=\mathrm{W}_{\mathrm{k}} \overrightarrow{\mathrm{U}}_{\mathrm{k}}+\mathrm{e}_{\mathrm{k}}
$$

where

$$
\begin{aligned}
& \mathrm{Y}_{\mathrm{k}}=\mathrm{D}_{\mathrm{k}}^{-1}\left[\begin{array}{c}
\hat{\overrightarrow{\mathrm{U}}}_{\mathrm{k} \mid \mathrm{k}-1} \\
\overrightarrow{\mathrm{z}}_{\mathrm{k}}
\end{array}\right] \\
& \mathrm{W}_{\mathrm{k}}=\mathrm{D}_{\mathrm{k}}^{-1}\left[\begin{array}{c}
\mathrm{I} \\
\mathrm{H}_{\mathrm{k}}
\end{array}\right] \\
& \mathrm{e}_{\mathrm{k}}=\mathrm{D}_{\mathrm{k}}^{-1} \mathrm{c}_{\mathrm{k}}
\end{aligned}
$$

since

$$
\mathrm{E}\left[\mathrm{e}_{\mathrm{k}} \mathrm{e}_{\mathrm{k}}^{\mathrm{T}}\right]=\mathrm{I}
$$

where $e_{k}$ is a white residual error. Here, the following $\mathrm{CC}$ based cost function is proposed:

$$
\mathrm{M}_{\mathrm{N}}\left(\overrightarrow{\mathrm{U}}_{\mathrm{k}}\right)=\frac{1}{\mathrm{~N}} \sum_{\mathrm{i}=1}^{\mathrm{N}} \mathrm{G}_{\Omega}\left(\mathrm{y}_{\mathrm{i}_{\mathrm{k}}}-\mathrm{w}_{\mathrm{i}_{\mathrm{k}}} \overrightarrow{\mathrm{U}}_{\mathrm{k}}\right)
$$

where $\mathrm{y}_{\mathrm{i}_{\mathrm{k}}}$ is the $\mathrm{i}^{\text {th }}$ element of $\mathrm{Y}_{\mathrm{k}}, \mathrm{w}_{\mathrm{i}_{\mathrm{k}}}$ is the $\mathrm{i}^{\text {th }}$ row of $\mathrm{W}_{\mathrm{k}}$, and $\mathrm{N}=\mathrm{n}+\mathrm{m}$ is the dimension of $\mathrm{Y}_{\mathrm{k}}$. For CC, the optimal estimation of $\overrightarrow{\mathrm{U}}_{\mathrm{k}}$ is:

$$
\hat{\overrightarrow{\mathrm{U}}}_{\mathrm{k}}=\arg \max _{\overrightarrow{\mathrm{U}}_{\mathrm{k}}} \mathrm{M}_{\mathrm{N}}\left(\overrightarrow{\mathrm{U}}_{\mathrm{k}}\right)=\arg \max _{\overrightarrow{\mathrm{U}}_{\mathrm{k}}} \sum_{\mathrm{i}=1}^{\mathrm{N}} \mathrm{G}_{\Omega}\left(\mathrm{e}_{\mathrm{i}_{\mathrm{k}}}\right)
$$

where $e_{i_{k}}$ is the $i^{\text {th }}$ element of $e_{k}$ :

$$
\mathrm{e}_{\mathrm{i}_{\mathrm{k}}}=\mathrm{y}_{\mathrm{i}_{\mathrm{k}}}-\mathrm{w}_{\mathrm{i}_{\mathrm{k}}} \overrightarrow{\mathrm{U}}_{\mathrm{k}}
$$

Thus, the optimal solution can be made available by solving:

$$
\frac{\partial \mathrm{M}_{\mathrm{N}}\left(\overrightarrow{\mathrm{U}}_{\mathrm{k}}\right)}{\partial \overrightarrow{\mathrm{U}}_{\mathrm{k}}}=\sum_{\mathrm{i}=1}^{\mathrm{N}}\left[\mathrm{G}_{\Omega}\left(\mathrm{e}_{\mathrm{i}_{\mathrm{k}}} \mathrm{w}_{\mathrm{i}_{\mathrm{k}}}^{\mathrm{T}}\right)\left(\mathrm{y}_{\mathrm{i}_{\mathrm{k}}}-\mathrm{w}_{\mathrm{i}_{\mathrm{k}}} \overrightarrow{\mathrm{U}}_{\mathrm{k}}\right)\right]=0
$$

According to Eq. (25), Eq. (29) is obtained:

$$
\overrightarrow{\mathrm{U}}_{\mathrm{k}}=\left\{\sum_{\mathrm{i}=1}^{\mathrm{N}}\left[\mathrm{G}_{\Omega}\left(\mathrm{e}_{\mathrm{i}_{\mathrm{k}}} \mathrm{w}_{\mathrm{i}_{\mathrm{k}}}^{\mathrm{T}} \mathrm{w}_{\mathrm{i}_{\mathrm{k}}}\right)\right]\right\}^{-1} \times \sum_{\mathrm{i}=1}^{\mathrm{N}}\left[\mathrm{G}_{\Omega}\left(\mathrm{e}_{\mathrm{i}_{\mathrm{k}}} \mathrm{w}_{\mathrm{i}_{\mathrm{k}}}^{\mathrm{T}} \mathrm{y}_{\mathrm{i}_{\mathrm{k}}}\right)\right]
$$

where $e_{i}=y_{i_{k}}-w_{i_{k}} \vec{U}_{k}$, and Eq. (32)'s optimum solution is a fixed-point equation of $\vec{U}_{k}$. It can be restated as:

$$
\overrightarrow{\mathrm{U}}_{\mathrm{k}}=\mathrm{f}_{\mathrm{a}}\left(\overrightarrow{\mathrm{U}}_{\mathrm{k}}\right)
$$


with

$$
\mathrm{f}_{\mathrm{a}}\left(\overrightarrow{\mathrm{U}}_{\mathrm{k}}\right)=\left\{\sum_{\mathrm{i}=1}^{\mathrm{N}}\left[\mathrm{G}_{\Omega}\left(\mathrm{y}_{\mathrm{i}_{\mathrm{k}}}-\mathrm{w}_{\mathrm{i}_{\mathrm{k}}} \overrightarrow{\mathrm{U}}_{\mathrm{k}}\right) \mathrm{w}_{\mathrm{i}_{\mathrm{k}}}^{\mathrm{T}} \mathrm{w}_{\mathrm{i}_{\mathrm{k}}}\right]\right\}^{-1} \times \sum_{\mathrm{i}=1}^{\mathrm{N}}\left[\mathrm{G}_{\Omega}\left(\mathrm{y}_{\mathrm{i}_{\mathrm{k}}}-\mathrm{w}_{\mathrm{i}_{\mathrm{k}}} \overrightarrow{\mathrm{U}}_{\mathrm{k}}\right) \mathrm{w}_{\mathrm{i}_{\mathrm{k}}}^{\mathrm{T}} \mathrm{y}_{\mathrm{i}_{\mathrm{k}}}\right]
$$

At this stage, a fixed-point iterative technique can be quickly made available as:

$$
\overrightarrow{\mathrm{U}}_{\mathrm{k}_{\mathrm{n}+1}}=\mathrm{f}_{\mathrm{a}}\left(\overrightarrow{\mathrm{U}}_{\mathrm{n}}\right)
$$

where $\vec{U}_{k_{n}}$ gives the solution against fixed iteration "n". The fixed-point Eq. (29) can be rewritten as:

$$
\overrightarrow{\mathrm{U}}_{\mathrm{k}}=\left(\mathrm{W}_{\mathrm{k}}^{\mathrm{T}} \mathrm{X}_{\mathrm{k}} \mathrm{W}_{\mathrm{k}}\right)^{-1} \mathrm{~W}_{\mathrm{k}}^{\mathrm{T}} \mathrm{X}_{\mathrm{k}} \mathrm{Y}_{\mathrm{k}}
$$

where

$$
X_{k}=\left[\begin{array}{cc}
X_{k}^{a} & 0 \\
0 & X_{k}^{b}
\end{array}\right]
$$

with

$$
\begin{aligned}
& \mathrm{X}_{\mathrm{k}}^{\mathrm{a}}=\operatorname{diag}\left\{\mathrm{G}_{\Omega}\left[\mathrm{e}_{\mathrm{r}_{\mathrm{l}_{\mathrm{k}}}}, \ldots . . \mathrm{G}_{\Omega}\left(\mathrm{e}_{\mathrm{r}_{\mathrm{n}_{\mathrm{k}}}}\right)\right]\right\} \\
& \mathrm{X}_{\mathrm{k}}^{\mathrm{b}}=\operatorname{diag}\left\{\mathrm{G}_{\Omega}\left[\mathrm{e}_{\mathrm{r}_{\mathrm{n}+\mathrm{l}_{\mathrm{k}}}}, \ldots . . \mathrm{G}_{\Omega}\left(\mathrm{e}_{\mathrm{r}_{\mathrm{n}+\mathrm{m}_{\mathrm{k}}}}\right)\right]\right\}
\end{aligned}
$$

Eq. (33) can be further rewritten as per the following:

$$
\overrightarrow{\mathrm{U}}_{\mathrm{k}}=\hat{\overrightarrow{\mathrm{U}}}_{\mathrm{k} \mid \mathrm{k}-1}+\overline{\mathrm{K}}_{\mathrm{k}}\left(\overrightarrow{\mathrm{Z}}_{\mathrm{k}}-\mathrm{H}_{\mathrm{k}} \hat{\overrightarrow{\mathrm{U}}}_{\mathrm{k} \mid \mathrm{k}-1}\right)
$$

where

$$
\left\{\begin{array}{c}
\overline{\mathrm{K}}_{\mathrm{k}}=\overline{\mathrm{P}}_{\mathrm{k} \mid \mathrm{k}-1} \mathrm{H}_{\mathrm{k}}^{\mathrm{T}}\left(\mathrm{H}_{\mathrm{k}} \overline{\mathrm{P}}_{\mathrm{k} \mid \mathrm{k}-1} \mathrm{H}_{\mathrm{k}}^{\mathrm{T}} \overline{\mathrm{R}}_{\mathrm{k}}\right)^{-1} \\
\overline{\mathrm{P}}_{\mathrm{k} \mid \mathrm{k}-1}=\mathrm{D}_{\mathrm{p}_{\mathrm{k} \mid \mathrm{k}-1}} \mathrm{X}_{\mathrm{k}}^{\mathrm{a}^{-1}} \mathrm{D}_{\mathrm{p}_{\mathrm{k} k \mathrm{k}-1}^{\mathrm{T}}}^{\mathrm{T}} \\
\overline{\mathrm{R}}_{\mathrm{k}}=\mathrm{D}_{\mathrm{r}_{\mathrm{k}}} \mathrm{X}_{\mathrm{k}}^{\mathrm{b}^{-1} \mathrm{D}_{\mathrm{r}_{\mathrm{k}}}^{\mathrm{T}}}
\end{array}\right\}
$$

\subsection{Steps in computing $C K F$}

Eq. (37) is a fixed-point type for $\vec{U}_{k}$ as $\vec{K}_{k}$ is dependent on $\vec{P}_{k \mid k-1}$ and $\vec{R}_{k}$, which are related to $\vec{U}_{k}$ via $X_{k}^{a}$ and $X_{k}^{b}$. Hence, the optimal solution of Eq. (37) also depends on the prior estimate $\overrightarrow{\mathrm{U}}_{\mathrm{k} \mid \mathrm{k}-1}$, which can be computed by Eq. (12) utilizing the latest estimate $\overrightarrow{\mathrm{U}}_{\mathrm{k}-1 \mid \mathrm{k}-1}$. From the above assumptions, the proposed CKF algorithm can be summed up as follows:

Step 1: A proper kernel bandwidth $\Omega$ is selected along with a positive number $\xi$. An initial estimate $\widehat{\overrightarrow{\mathrm{U}}}_{0 \mid 0}$ and an initial covariance matrix $\mathrm{P}_{0 \mid 0}$ is assumed with $\mathrm{k}=1$.

Step 2: Eq. (12) and Eq. (13) are used to obtain $\widehat{\overrightarrow{\mathrm{U}}}_{\mathrm{k} \mid \mathrm{k}-1}$ and $\mathrm{P}_{\mathrm{k} \mid \mathrm{k}-1}$. Cholesky decomposition is used to obtain $\mathrm{D}_{\mathrm{p}_{\mathrm{k} \mid \mathrm{k}-1}}$. 
Step 3: It is assumed that $n=1$ and $\widehat{\vec{U}}_{k \mid k_{n}}=\widehat{\vec{U}}_{k \mid k-1}$, where $\widehat{\vec{U}}_{k \mid k_{n}}$ represents the estimated state at iteration " $n$ " of the fixed-point type.

Step 4: Eqs. (39)-(45) are used to compute $\widehat{\widehat{U}}_{\mathrm{k} \mid \mathrm{k}_{\mathrm{n}}}$.

$$
\hat{\overrightarrow{\mathrm{U}}}_{\mathrm{k} \mid \mathrm{k}_{\mathrm{n}}}=\hat{\overrightarrow{\mathrm{U}}}_{\mathrm{k} \mid \mathrm{k}-1}+\overline{\mathrm{K}}_{\mathrm{k}}\left(\overrightarrow{\mathrm{z}}_{\mathrm{k}}-\mathrm{H}_{\mathrm{k}} \hat{\overrightarrow{\mathrm{U}}}_{\mathrm{k} \mid \mathrm{k}-1}\right)
$$

with

$$
\begin{aligned}
& \tilde{\mathrm{K}}_{\mathrm{k}}=\tilde{\mathrm{P}}_{\mathrm{k} \mid \mathrm{k}-1} \mathrm{H}_{\mathrm{k}}^{\mathrm{T}}\left(\mathrm{H}_{\mathrm{k}} \tilde{\mathrm{P}}_{\mathrm{k} \mid \mathrm{k}-1} \mathrm{H}_{\mathrm{k}}^{\mathrm{T}}+\tilde{\mathrm{R}}_{\mathrm{k}}\right)^{-1} \\
& \tilde{\mathrm{P}}_{\mathrm{k} \mid \mathrm{k}-1}=\mathrm{D}_{\mathrm{p}_{\mathrm{k} \mid \mathrm{k}-1}} \tilde{\mathrm{X}}_{\mathrm{k}}^{\mathrm{a}}{ }^{-1} \mathrm{D}_{\mathrm{p}_{\mathrm{k} \mid \mathrm{k}-1}}^{\mathrm{T}} \\
& \tilde{\mathrm{R}}_{\mathrm{k}}=\mathrm{D}_{\mathrm{r}_{\mathrm{k}}} \tilde{\mathrm{X}}_{\mathrm{k}}^{\mathrm{b}} \mathrm{D}_{\mathrm{r}_{\mathrm{k}}}^{\mathrm{T}} \\
& \tilde{\mathrm{X}}_{\mathrm{k}}^{\mathrm{a}}=\operatorname{diag}\left\{\mathrm{G}_{\Omega}\left[\tilde{\mathrm{e}}_{\mathrm{1}_{\mathrm{k}}}, \ldots . . \mathrm{G}_{\Omega}\left(\tilde{\mathrm{e}}_{\mathrm{n}_{\mathrm{k}}}\right)\right]\right\} \\
& \tilde{\mathrm{X}}_{\mathrm{k}}^{\mathrm{b}}=\operatorname{diag}\left\{\mathrm{G}_{\Omega}\left[\tilde{\mathrm{e}}_{\mathrm{n}+\mathrm{1}_{\mathrm{k}}}, \ldots . . \mathrm{G}_{\Omega}\left(\tilde{\mathrm{e}}_{\mathrm{n}+\mathrm{m}_{\mathrm{k}}}\right)\right]\right\} \\
& \tilde{\mathrm{e}}_{\mathrm{i}_{\mathrm{k}}}=\mathrm{y}_{\mathrm{i}_{\mathrm{k}}}-\mathrm{w}_{\mathrm{i}_{\mathrm{k}}} \hat{\overrightarrow{\mathrm{U}}}_{\mathrm{k} \mid \mathrm{k}_{\mathrm{n}-1}}
\end{aligned}
$$

Step 5: The estimation of the current step and the last step is compared. For Eq. (46) to be valid, set $\widehat{\overrightarrow{\mathrm{U}}}_{\mathrm{k} \mid \mathrm{k}}=\widehat{\widehat{\mathrm{U}}}_{\mathrm{k} \mid \mathrm{k}_{\mathrm{n}}}$ and proceed to step 6. Otherwise, $n+1 \rightarrow n$, and go back to step 4 .

$$
\frac{\left\|\hat{\overrightarrow{\mathrm{U}}}_{\mathrm{k} \mid \mathrm{k}_{\mathrm{n}}}-\hat{\overrightarrow{\mathrm{U}}}_{\mathrm{k} \mid \mathrm{k}_{\mathrm{n}-1}}\right\|}{\left\|\hat{\overrightarrow{\mathrm{U}}}_{\mathrm{k} \mid \mathrm{k}_{\mathrm{n}-1}}\right\|} \leq \xi
$$

Step 6: The posterior covariance matrix is updated by Eq. (47), $k+1 \rightarrow \mathrm{k}$, and the return is made to step 2.

$$
\mathrm{P}_{\mathrm{k} \mid \mathrm{k}}=\left(\mathrm{I}-\tilde{\mathrm{K}}_{\mathrm{k}} \mathrm{H}_{\mathrm{k}}\right) \mathrm{P}_{\mathrm{k} \mid \mathrm{k}-1}\left(\mathrm{I}-\tilde{\mathrm{K}}_{\mathrm{k}} \mathrm{H}_{\mathrm{k}}\right)^{\mathrm{T}}+\tilde{\mathrm{K}}_{\mathrm{k}} \mathrm{R}_{\mathrm{k}} \tilde{\mathrm{K}}_{\mathrm{k}}^{\mathrm{T}}
$$

The CKF algorithm reacts to Eqs. (12)-(13), (39)-(45), and (47). Note that $\mathrm{X}_{\mathrm{k}}^{\mathrm{a}}$ and $\mathrm{X}_{\mathrm{k}}^{\mathrm{b}}$ are diagonal matrices; obtaining their inverse matrices is straightforward. CKF uses a fixed-point algorithm, unlike traditional KF, to update the posterior estimate. In this case, $\xi$ offers a condition/threshold stop. Since iteration's initial value is set at a prior estimate $\overrightarrow{\mathrm{U}}_{\mathrm{k} \mid \mathrm{k}-1}$, the optimum convergence occurs. Note that the solution is speedy (usually in several steps). Furthermore, in CKF, $\Omega$ is a vital parameter. A lower $\Omega$ value allows the algorithm more resilient to outliers, but with slow convergence; a higher $\Omega$ value means that CKF is similar to the ordinary KF. In practical implementations, $\Omega$ is set manually or optimized by trial and error methods.

\section{Data Collection, Results, and Discussion}

Aircraft landings require highly accurate position estimates with minimum variance. For this purpose, CKF is proposed in this study. The proposed CKF algorithm is developed based on the CC and the KF frame work. In this section, four positioning algorithms (i.e., least square estimator (LSE) [26], KF [28], EKF [26, 30], and CKF) are evaluated with the dual-frequency GPS receiver data collected from the Indian subcontinent's southern region. 


\subsection{Experimental setup and data collection}

The data used to evaluate the navigation algorithms performance concerning the IISc GPS receiver in Bangalore is collected from the Scripps Orbit and Permanent Array Centre (SOPAC) database. The GPS data available in the database follows the compressed receiver independent exchange format (RINEX) or Hatanaka format. The files with Hatanaka extension (.d) are converted to RINEX format using Hatanaka to RINEX conversion program or RNXCMP software (available in SOPAC). The observation and navigation data files are retrieved from the RINEX file then input to the interpolator to estimate the GPS receiver position. The observation data file comprises two types of pseudo-range information for two different frequencies (L1 and L2), recorded for every $30 \mathrm{sec}$.

C/A code pseudo-range is obtained from L1 frequency, and the P-code pseudo-range is obtained from L2 frequency. In contrast, the navigation data file provides the satellite orbital data, which helps determine the satellite position. For every two hours, the navigation data is available, i.e., the initial data will only appear at 00:00:00 hours. The following data will only be available at 02:00:00 hours until 24 hours a day. The data in between every two hours is interpolated. This process generates the necessary data to find a navigation solution using the navigation solution algorithms. Fig. 2 demonstrates the different steps involved in the estimation of the GPS receiver position.

The real-time GPS data is collected over 22 hours on $1^{\text {st }}$ January 2020, $16^{\text {th }}$ August 2020, and $19^{\text {th }}$ December 2020 respectively from a dual-frequency GPS receiver located at IISc in Bangalore (latitude: $13.021^{\circ} \mathrm{N} /$ longitude: $77.5^{\circ} \mathrm{E}$ ), India. The collected data is processed and used in receiver position estimation. The IISc GPS receiver is located in the surveyed location, and $\mathrm{X}=1337936.309 \mathrm{~m}, \mathrm{Y}=6070317.116 \mathrm{~m}$, and $\mathrm{Z}=1427876.908 \mathrm{~m}$ are the receiver position of the earth-centered and earth-fixed (ECEF) coordinates. The simulation results of the proposed CKF algorithm for the data set taken on three different dates are almost identical. Thus, the best results achieved for the data set taken on $1^{\text {st }}$ January 2020 is presented in this study for simplicity. Because the IISc GPS receiver is a static receiver, no significant differences are observed on the different data sets.

The visibility of satellites over this region on $1^{\text {st }}$ January 2020 is shown in Fig. 3. It may be noted that the satellite pseudorandom number (SV PRN) having the visibility in this location are 1, 2, 3, 4, 5, 6, 7, 8, 9, 10, 11, 12, 13, 14, 15, 16, 17, $18,19,20,21,22,23,24,26,27,28,29,30$ and 31 . The initial receiver's position is chosen very close to the surveyed receiver position to compare the four algorithm's performance. This is because the recursive algorithms (i.e., KF and EKF) require some time for position convergence compared with the iterative (LSE) algorithm. This convergence time is reduced with proper initial position coordinates. The initial guess used for position estimation of IISc receiver (latitude: $13.021^{\circ} \mathrm{N} /$ longitude: $\left.77.5^{\circ} \mathrm{E}\right)$ is $\mathrm{X}=1337900 \mathrm{~m}, \mathrm{Y}=6070300 \mathrm{~m}$, and $\mathrm{Z}=1427800 \mathrm{~m}$.

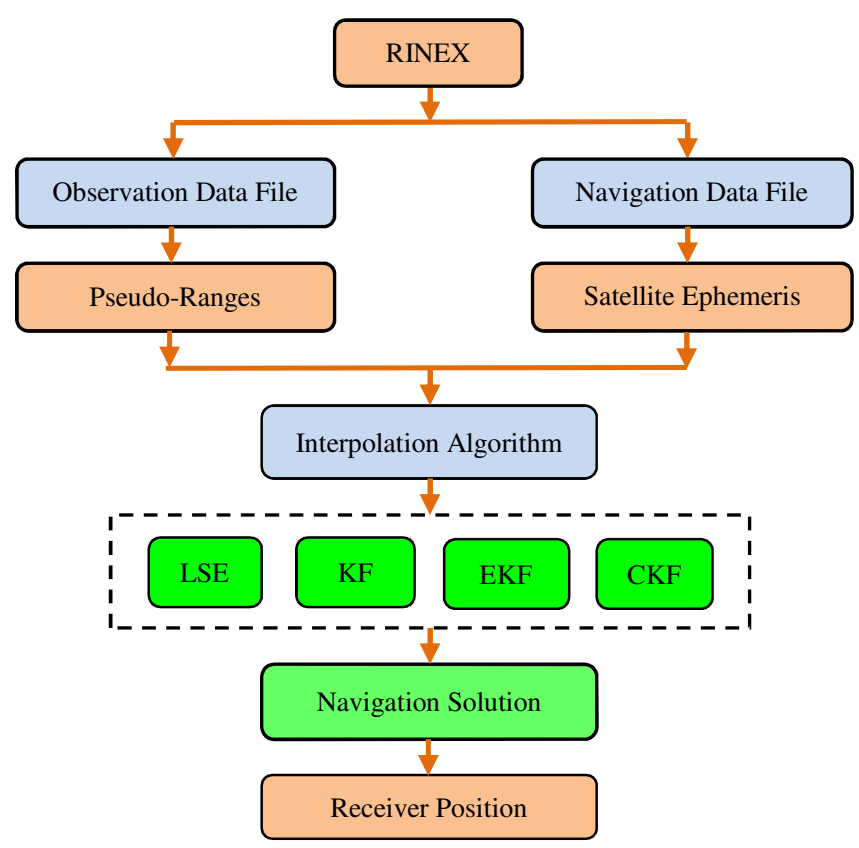

Fig. 2 GPS data processing for navigation solution 


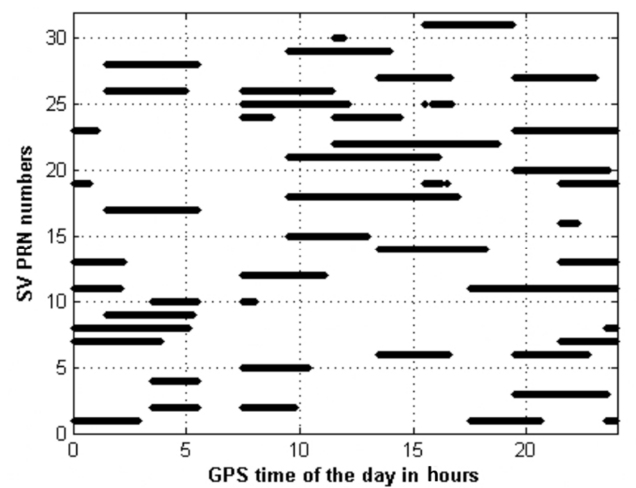

Fig. 3 Visibility of satellites over the entire day of $1^{\text {st }}$ January 2020 (IISc)

The obtained estimated receiver positions are compared with the surveyed position to measure the position error due to the four algorithms, i.e., LSE, KF, EKF, and CKF. These results are presented in Tables 1 and 2 in the next section, and the given values are the estimated mean values of 22 hours of the data.

\subsection{Performance analysis}

The obtained estimated mean positions represented in Table 1 are compared concerning X-, Y-, and Z-directions with the surveyed position. Furthermore, the observed minimum and maximum position estimates corresponding to the LSE, KF, EKF, and CKF algorithms are shown in Table 1. Fig. 4 shows that the estimated receiver mean positions over an hour reported due to the four algorithms are compared with the true receiver position in 3-dimensional surface. Additionally, Fig. 5 shows that the final estimated mean position reported due to the four algorithms is compared with the true receiver position in 3-dimensional surface. It is observed that from Fig. 4, the estimated receiver mean positions over an hour due to the CKF algorithm is accurate and precise, and seems close to the true receiver position with minimal variance in contrast to the LSE, KF, and EKF algorithms. Even though the estimated receiver mean positions using the EKF algorithm seems close to the true position, they are scattered widely, which exhibit high variance compared to the CKF algorithm. Furthermore, the estimated mean positions using the LSE and KF algorithms are far from the true receiver position. It is seen that from Fig. 5 the final estimated receiver's mean position due to the CKF algorithm is adjacent to the true receiver position in contrast to the LSE, KF, and EKF algorithms. Furthermore, the LSE and KF algorithms' final estimated positions are distant from the true receiver position.

Table 1 Comparison of the estimated mean position among four algorithms in $\mathrm{X}$, Y, and Z- directions

\begin{tabular}{|c|c|c|c|c|c|c|c|c|c|c|c|c|}
\hline \multirow{3}{*}{$\begin{array}{c}\text { GPS } \\
\text { time } \\
(\mathrm{hr})\end{array}$} & \multicolumn{12}{|c|}{ Estimated receiver mean position error (meters) } \\
\hline & \multicolumn{4}{|c|}{ X-direction } & \multicolumn{4}{|c|}{ Y-direction } & \multicolumn{4}{|c|}{ Z-direction } \\
\hline & LSE & KF & EKF & CKF & LSE & KF & EKF & CKF & LSE & KF & EKF & CKF \\
\hline $00-01$ & 1337903.12 & 1337905.32 & 1337922.63 & 1337913.12 & 6070350.23 & 6070323.24 & 6070345.29 & 6070335.23 & 1427889.27 & 1427885.34 & 1427885.93 & 1427886.27 \\
\hline 01-02 & 1337899.93 & 1337901.05 & 1337924.76 & 1337910.31 & 6070339.69 & 6070328.91 & 6070339.55 & 6070328.71 & 1427883.12 & 1427883.62 & 1427880.00 & 1427883.02 \\
\hline $02-03$ & 1337891.54 & 1337892.38 & 1337914.47 & 1337900.67 & 6070327.83 & 6070336.51 & 6070335.69 & 6070312.89 & 1427881.78 & 1427882.37 & 1427875.72 & 1427881.60 \\
\hline 03-04 & 1337890.93 & 1337890.29 & 1337924.65 & 1337900.96 & 6070339.67 & 6070334.46 & 6070337.36 & 6070328.78 & 1427885.15 & 1427884.16 & 1427877.31 & 1427881.93 \\
\hline 04-05 & 1337893.99 & 1337892.60 & 1337920.65 & 1337904.01 & 6070350.44 & 6070343.43 & 6070340.54 & 6070335.42 & 1427884.55 & 1427884.33 & 1427880.53 & 1427880.96 \\
\hline 05-06 & 1337896.30 & 1337897.07 & 1337920.54 & 1337905.63 & 6070343.93 & 6070343.68 & 6070341.73 & 6070329.33 & 1427883.87 & 1427885.76 & 1427872.03 & 1427882.04 \\
\hline 06-07 & 1337901.57 & 1337900.67 & 1337908.29 & 1337911.80 & 6070341.76 & 6070338.19 & 6070331.19 & 6070327.86 & 1427883.53 & 1427882.41 & 1427856.99 & 1427880.20 \\
\hline 07-08 & 1337903.29 & 1337901.75 & 1337907.51 & 1337914.85 & 6070347.08 & 6070340.84 & 6070322.48 & 6070335.16 & 1427882.49 & 1427880.18 & 1427854.47 & 1427879.75 \\
\hline 08-09 & 1337906.33 & 1337905.17 & 1337917.10 & 1337919.72 & 6070349.25 & 6070337.88 & 6070334.83 & 6070334.42 & 1427885.71 & 1427883.77 & 1427867.88 & 1427884.14 \\
\hline 09-10 & 1337910.22 & 1337910.15 & 1337909.41 & 1337920.95 & 6070348.58 & 6070347.47 & 6070344.67 & 6070335.11 & 1427889.48 & 1427886.16 & 1427878.88 & 1427885.14 \\
\hline $10-11$ & 1337911.86 & 1337914.59 & 1337902.37 & 1337923.50 & 6070356.41 & 6070365.63 & 6070342.40 & 6070341.24 & 1427884.32 & 1427884.87 & 1427877.43 & 1427880.68 \\
\hline $11-12$ & 1337909.82 & 1337911.22 & 1337906.59 & 1337919.83 & 6070359.91 & 6070368.51 & 6070335.47 & 6070346.41 & 1427883.29 & 1427884.06 & 1427870.64 & 1427878.42 \\
\hline $12-13$ & 1337903.74 & 1337901.66 & 1337908.32 & 1337913.20 & 6070364.76 & 6070361.12 & 6070328.99 & 6070351.20 & 1427882.36 & 1427882.02 & 1427863.61 & 1427877.51 \\
\hline $13-14$ & 1337901.95 & 1337895.45 & 1337909.68 & 1337911.35 & 6070360.82 & 6070347.61 & 6070333.95 & 6070343.99 & 1427881.82 & 1427880.40 & 1427867.87 & 1427878.04 \\
\hline 14-15 & 1337896.45 & 1337888.74 & 1337908.35 & 1337905.24 & 6070346.28 & 6070346.94 & 6070332.28 & 6070330.80 & 1427882.28 & 1427883.17 & 1427867.60 & 1427878.67 \\
\hline $15-16$ & 1337894.50 & 1337891.28 & 1337910.58 & 1337903.29 & 6070344.96 & 6070346.75 & 6070327.11 & 6070329.23 & 1427877.98 & 1427881.11 & 1427863.77 & 1427874.84 \\
\hline 16-17 & 1337903.15 & 1337900.86 & 1337913.27 & 1337913.97 & 6070333.43 & 6070346.09 & 6070335.51 & 6070327.84 & 1427881.53 & 1427879.51 & 1427874.42 & 1427880.79 \\
\hline $17-18$ & 1337906.92 & 1337904.23 & 1337907.60 & 1337916.38 & 6070333.17 & 6070344.63 & 6070342.90 & 6070327.91 & 1427882.97 & 1427882.89 & 1427883.84 & 1427880.30 \\
\hline 18-19 & 1337905.62 & 1337904.51 & 1337902.36 & 1337916.31 & 6070345.23 & 6070338.72 & 6070340.29 & 6070331.19 & 1427881.25 & 1427880.76 & 1427881.13 & 1427879.19 \\
\hline 19-20 & 1337908.06 & 1337906.64 & 1337905.44 & 1337918.24 & 6070341.68 & 6070340.07 & 6070340.93 & 6070326.48 & 1427878.51 & 1427878.33 & 1427881.69 & 1427875.62 \\
\hline $20-21$ & 1337904.13 & 1337905.36 & 1337909.79 & 1337915.31 & 6070337.12 & 6070334.97 & 6070340.80 & 6070322.43 & 1427879.72 & 1427882.01 & 1427881.45 & 1427875.36 \\
\hline $21-22$ & 1337901.35 & 1337903.13 & 1337903.40 & 1337911.90 & 6070343.15 & 6070329.47 & 6070341.27 & 6070328.12 & 1427886.40 & 1427884.63 & 1427881.87 & 1427883.54 \\
\hline$\mu$ & 1337902.04 & 1337901.10 & 1337911.72 & 1337912.30 & 6070345.70 & 6070342.96 & 6070337.05 & 6070332.26 & 1427883.24 & 1427882.81 & 1427873.87 & 1427880.36 \\
\hline$\sigma$ & 5.98 & 7.03 & 7.06 & 6.59 & 9.23 & 11.14 & 5.94 & 7.51 & 2.88 & 2.11 & 8.75 & 2.43 \\
\hline$\sigma^{2}$ & 35.75 & 49.46 & 49.83 & 43.49 & 85.21 & 124.15 & 35.32 & 56.37 & 8.30 & 4.46 & 76.60 & 5.92 \\
\hline
\end{tabular}

Note: $\mu$ is mean; $\sigma$ is standard deviation; $\sigma^{2}$ is variance. 


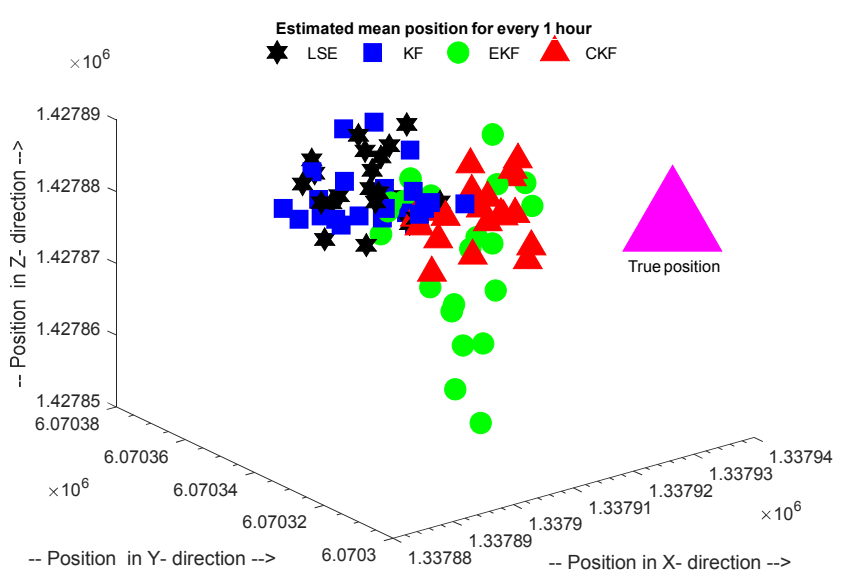

Fig. 4 Comparison of the estimated mean position among four algorithms in 3-dimensional surface

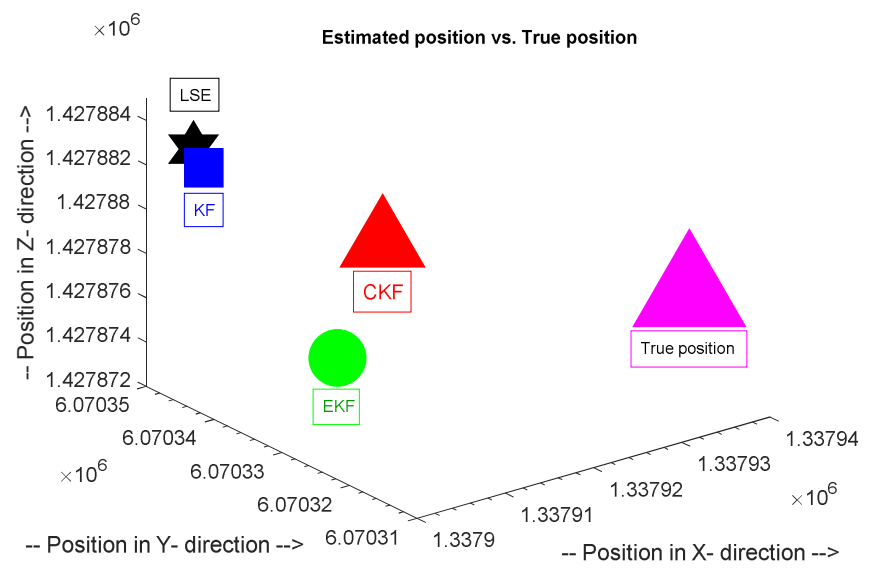

Fig. 5 Comparison of the estimated final mean position among four algorithms in 3-dimensional surface

\subsection{Error analysis}

Table 2 compares the error in the estimated mean position over an hour due to the LSE, KF, EKF, and CKF algorithms (in $\mathrm{X}$-, Y-, and Z-directions). The observed minimum and maximum error in position estimate corresponding to the four algorithms are shown in the table with bold numbers simultaneously with the mean, standard deviation, and variance. Fig. 6 represents the mean position error comparison over an hour among the four algorithms in 3-dimensional surface in addition to the above plots.

Table 2 Comparison of mean position error among four algorithms in $\mathrm{X}$, Y, and Z- directions

\begin{tabular}{|c|c|c|c|c|c|c|c|c|c|c|c|c|}
\hline \multirow{3}{*}{$\begin{array}{c}\text { GPS } \\
\text { time } \\
\text { (hr) }\end{array}$} & \multicolumn{12}{|c|}{ Estimated receiver mean position error (meters) } \\
\hline & \multicolumn{4}{|c|}{$\mathrm{X}$-direction } & \multicolumn{4}{|c|}{ Y-direction } & \multicolumn{4}{|c|}{ Z-direction } \\
\hline & LSE & KF & EKF & CKF & LSE & KF & EKF & CKF & LSE & $\mathrm{KF}$ & EKF & CKF \\
\hline $00-01$ & 33.19 & 31.00 & 13.68 & 23.19 & 33.11 & 6.12 & 28.18 & 18.11 & 12.36 & 8.43 & 9.02 & 9.36 \\
\hline 01-02 & 36.38 & 35.26 & 11.55 & 26.00 & 22.57 & 11.79 & 22.44 & 11.59 & 6.21 & 6.71 & 3.09 & 6.11 \\
\hline $02-03$ & 44.77 & 43.93 & 21.84 & 35.64 & 10.72 & 19.39 & 18.57 & 4.23 & 4.87 & 5.46 & 1.19 & 4.69 \\
\hline $03-04$ & 45.38 & 46.03 & 11.66 & 35.35 & 22.56 & 17.34 & 20.25 & 11.66 & 8.24 & 7.25 & 0.40 & 5.02 \\
\hline 04-05 & 42.32 & 43.71 & 15.66 & 32.30 & 33.33 & 26.31 & 23.42 & 18.30 & 7.64 & 7.42 & 3.62 & 4.05 \\
\hline $05-06$ & 40.01 & 39.24 & 15.77 & 30.68 & 26.82 & 26.56 & 24.62 & 12.21 & 6.96 & 8.85 & 4.88 & 5.13 \\
\hline 06-07 & 34.74 & 35.64 & 28.02 & 24.51 & 24.65 & 21.07 & 14.07 & 10.74 & 6.62 & 5.50 & 19.92 & 3.29 \\
\hline $07-08$ & 33.02 & 34.56 & 28.80 & 21.46 & 29.96 & 23.72 & 5.36 & 18.04 & 5.58 & 3.27 & 22.44 & 2.84 \\
\hline 08-09 & 29.98 & 31.14 & 19.21 & 16.59 & 32.14 & 20.76 & 17.71 & 17.30 & 8.80 & 6.86 & 9.03 & 7.23 \\
\hline 09-10 & 26.09 & 26.16 & 26.90 & 15.36 & 31.47 & 30.35 & 27.56 & 17.99 & 12.57 & 9.25 & 1.98 & 8.23 \\
\hline $10-11$ & 24.46 & 21.72 & 33.94 & 12.81 & 39.30 & 48.51 & 25.29 & 24.12 & 7.41 & 7.96 & 0.53 & 3.77 \\
\hline $11-12$ & 26.49 & 25.09 & 29.72 & 16.48 & 42.79 & 51.39 & 18.35 & 29.29 & 6.38 & 7.15 & 6.27 & 1.51 \\
\hline $12-13$ & 32.57 & 34.65 & 27.99 & 23.11 & 47.64 & 44.00 & 11.87 & 34.08 & 5.45 & 5.11 & 13.30 & 0.60 \\
\hline $13-14$ & 34.36 & 40.87 & 26.63 & 24.96 & 43.70 & 30.49 & 16.83 & 26.87 & 4.91 & 3.49 & 9.04 & 1.13 \\
\hline $14-15$ & 39.87 & 47.57 & 27.96 & 31.07 & 29.17 & 29.82 & 15.16 & 13.68 & 5.37 & 6.26 & 9.31 & 1.76 \\
\hline $15-16$ & 41.81 & 45.04 & 25.73 & 33.02 & 27.85 & 29.63 & 10.00 & 12.11 & 1.07 & 4.20 & 13.14 & 2.07 \\
\hline $16-17$ & 33.16 & 35.45 & 23.04 & 22.34 & 16.31 & 28.97 & 18.39 & 10.72 & 4.62 & 2.60 & 2.49 & 3.88 \\
\hline $17-18$ & 29.39 & 32.09 & 28.71 & 19.93 & 16.06 & 27.51 & 25.79 & 10.79 & 6.06 & 5.98 & 6.93 & 3.39 \\
\hline $18-19$ & 30.69 & 31.80 & 33.95 & 20.00 & 28.11 & 21.60 & 23.17 & 14.07 & 4.34 & 3.85 & 4.22 & 2.28 \\
\hline $19-20$ & 28.26 & 29.67 & 30.87 & 18.07 & 24.57 & 22.95 & 23.82 & 9.36 & 1.60 & 1.42 & 4.79 & 1.29 \\
\hline $20-21$ & 32.18 & 30.95 & 26.52 & 21.00 & 20.01 & 17.85 & 23.68 & 5.31 & 2.81 & 5.10 & 4.54 & 1.55 \\
\hline $21-22$ & 34.96 & 33.19 & 32.91 & 24.41 & 26.03 & 12.35 & 24.16 & 11.00 & 9.49 & 7.72 & 4.97 & 6.63 \\
\hline$\mu$ & 34.27 & 35.21 & 24.59 & 24.01 & 28.58 & 25.84 & 19.94 & 15.52 & 6.33 & 5.90 & 3.04 & 3.90 \\
\hline$\sigma$ & 5.98 & 7.03 & 7.06 & 6.59 & 9.23 & 11.14 & 5.94 & 7.51 & 2.88 & 2.11 & 8.75 & 2.43 \\
\hline$\sigma^{2}$ & 35.75 & 49.46 & 49.83 & 43.49 & 85.21 & 124.15 & 35.32 & 56.37 & 8.30 & 4.46 & 76.60 & 5.92 \\
\hline
\end{tabular}




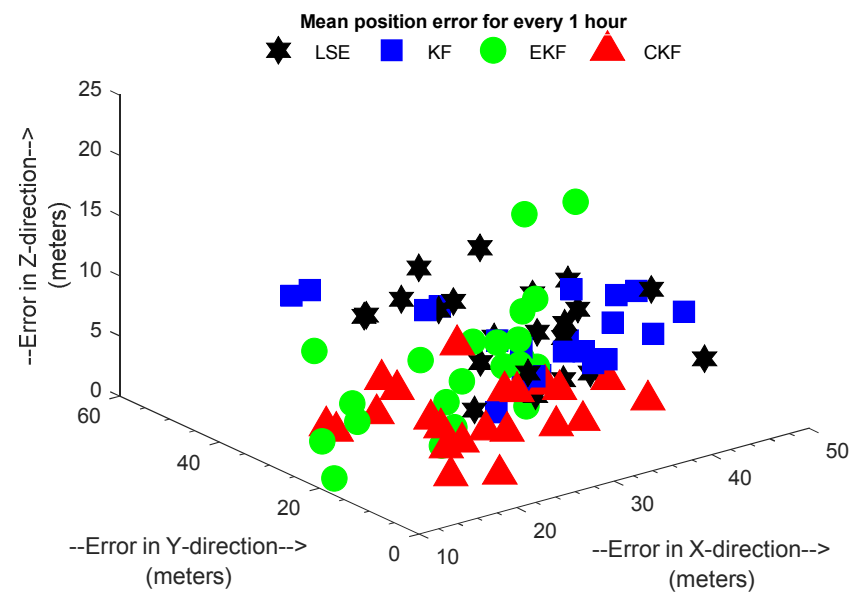

Fig. 6 Comparison of mean position error among four algorithms in 3-dimensional surface

The following key points are observed from the error analysis of the results:

(1) The proposed CKF algorithm provides significant accuracy improvement in position estimation concerning X-direction with a mean position error of $24.01 \mathrm{~m}$, which is less by $10.26 \mathrm{~m}$ due to LSE, $11.20 \mathrm{~m}$ due to KF, and $0.58 \mathrm{~m}$ due to EKF algorithms, respectively.

(2) Concerning Y-direction, the proposed CKF algorithm provides significant accuracy improvement in position estimation with a mean position error of $15.52 \mathrm{~m}$, which is less by $13.06 \mathrm{~m}$ due to LSE, $10.32 \mathrm{~m}$ due to KF, and $4.42 \mathrm{~m}$ due to EKF algorithms, respectively.

(3) For Z-direction, the proposed CKF algorithm provides significant accuracy improvement in position estimation with a mean position error of $3.90 \mathrm{~m}$, which is less by $2.43 \mathrm{~m}$ due to LSE and $2 \mathrm{~m}$ due to KF but higher by $0.86 \mathrm{~m}$ due to EKF algorithms; the mean position error of EKF algorithm is very low.

(4) The vertical position error (i.e., the error in Z-direction) of the proposed CKF algorithm ( $\left.\mu_{\mathrm{ze}}=3.90 \mathrm{~m}\right)$ is found to be less than the required vertical position accuracy of CAT-I $(4.5-7 \mathrm{~m})$ aircraft landings, i.e., $3.90 \mathrm{~m}<4.5-7 \mathrm{~m}$. This is accomplished by neglecting other correctable error sources.

\subsection{Statistical error characterization in 1-dimensional surface}

Figs. 7-9 show that the curves corresponding to the Gaussian distribution of position error in $\mathrm{X}, \mathrm{Y}$, and Z- directions due to four algorithms (LSE, KF, EKF, and CKF), along with the mean $(\mu)$, standard deviation $(\sigma)$, and $\pm 1 \sigma$ bound. Tables $3-5$ exhibit the histogram's statistical error distribution that is plotted in Figs. 7-9 in X, Y, and Z- directions, along with the obtained minimum and maximum error. The estimated position error for 22 hours of the data is partitioned into the number of bins, and these bins accommodate a specified range (based on the minimum and maximum error). The total estimated position error points are lying in those bins according to their error value.

It is noted from Table 3 and Fig. 7, concerning X- direction that mostly 88.1\% of the position errors lying within 25-46 $\mathrm{m}$ due to LSE, $90.4 \%$ of the errors are within $23-49 \mathrm{~m}$ due to KF, $72.3 \%$ of the errors are within $18-36 \mathrm{~m}$ due to EKF, and $86 \%$ of the errors are within 13-34 m due to CKF, respectively. It is noted from Table 4 and Fig. 8, concerning Y- direction that mostly $73.7 \%$ of the errors lie within $16-40 \mathrm{~m}$ due to LSE, $75.8 \%$ of the errors are within $10-40 \mathrm{~m}$ due to KF, $86.5 \%$ of the errors are within 7-28 $\mathrm{m}$ due to EKF, and 83\% of the errors are within 0-21 m due to CKF, respectively. It is noted from Table 5 and Fig. 9, concerning Z- direction that mostly $99.1 \%$ of the errors lie within 0-15 $\mathrm{m}$ due to LSE, $99.8 \%$ of the errors are within $0-19 \mathrm{~m}$ due to KF, $92.5 \%$ of the errors are within $0-19 \mathrm{~m}$ due to EKF, and $92.5 \%$ of the errors are within $0-10 \mathrm{~m} \mathrm{due} \mathrm{to} \mathrm{CKF}$, respectively. 
A normal or Gaussian curve of a probability distribution is produced by computing the 22-hour data statistics overlaid in Figs. 7-9. These curves simultaneously exhibit what a normal distribution seem and ease graphically representing the underlying truth. It is seen that there is a valid bell-shaped curve (red, blue, and black color bell-shaped curves) on Figs. 7-9. It is also evident whether GPS errors obey the normal distribution or the Gaussian one.

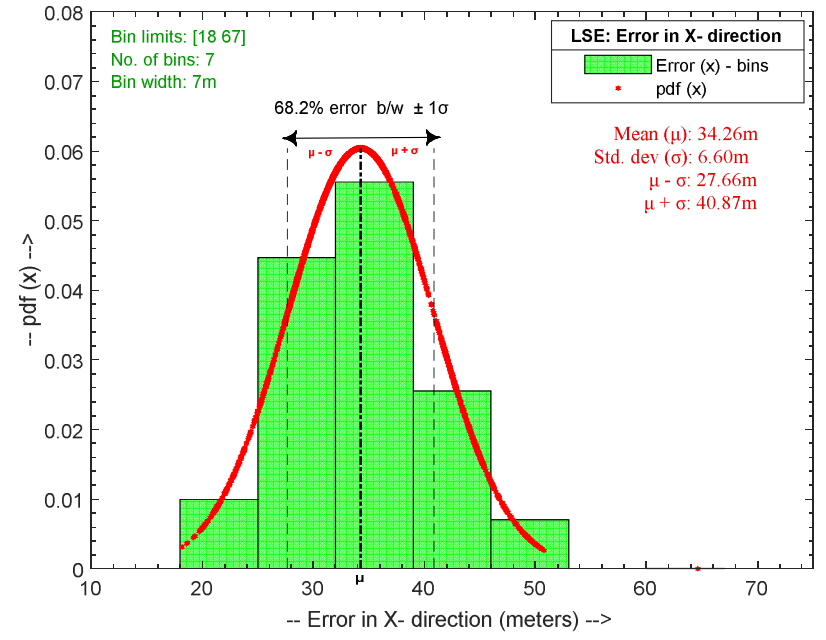

(a) Using LSE

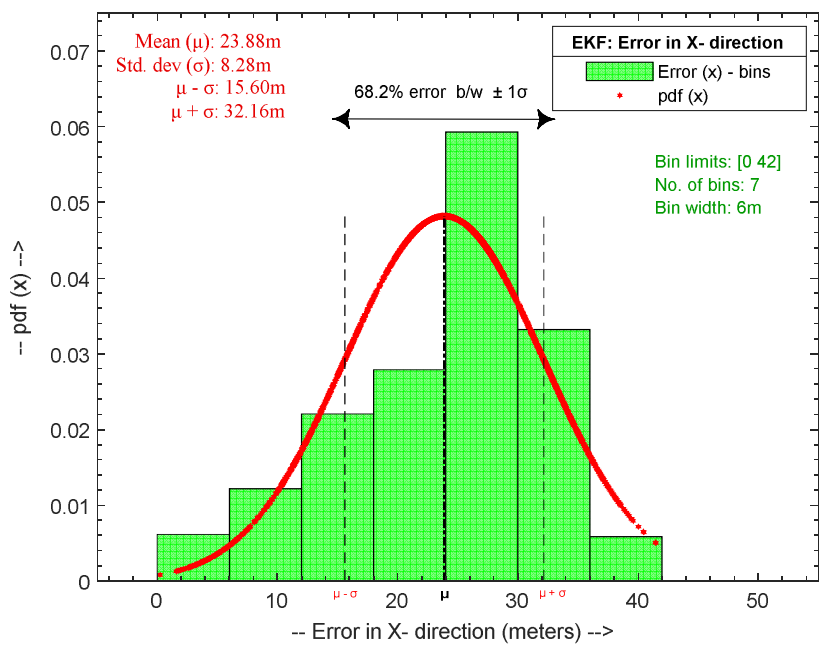

(c) Using EKF

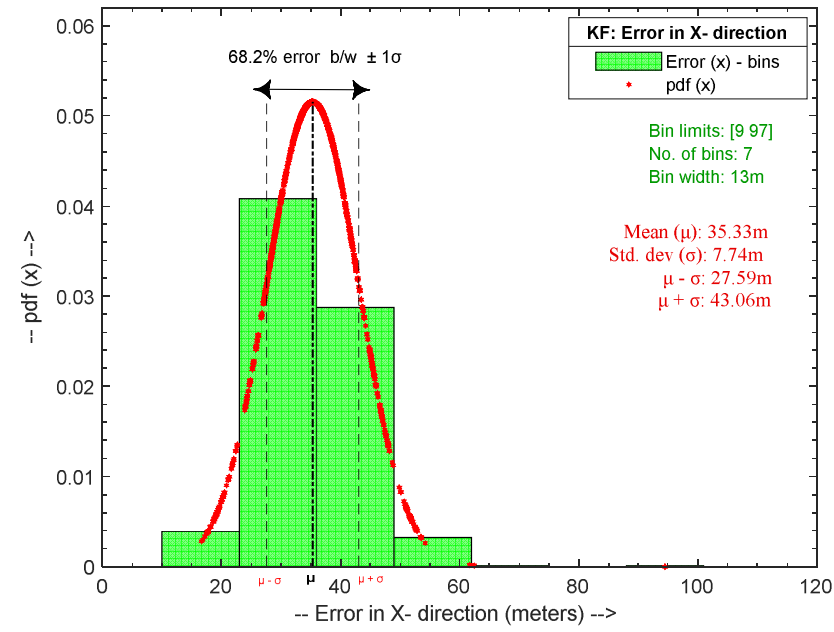

(b) Using KF

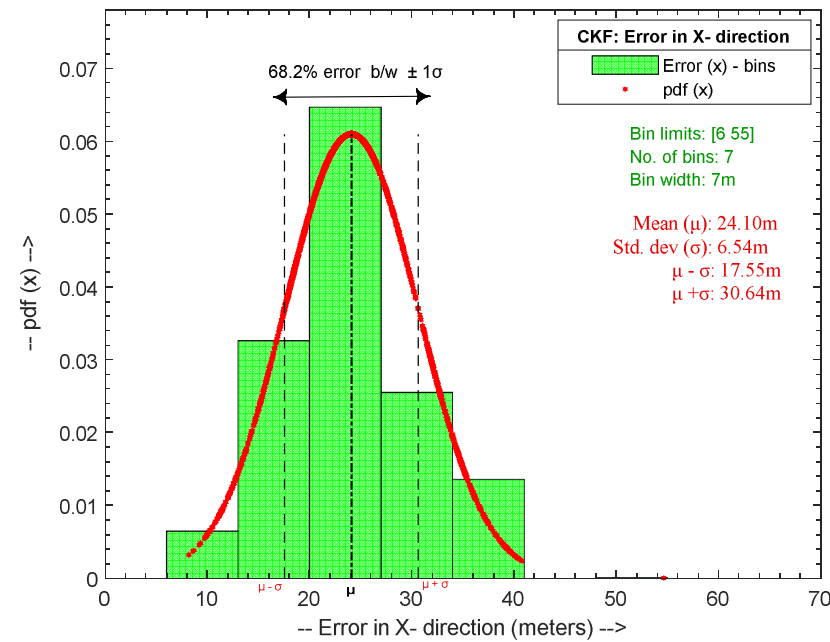

(d) Using CKF

Fig. 7 Gaussian distribution of position error in 1-dimensional surface in X-direction

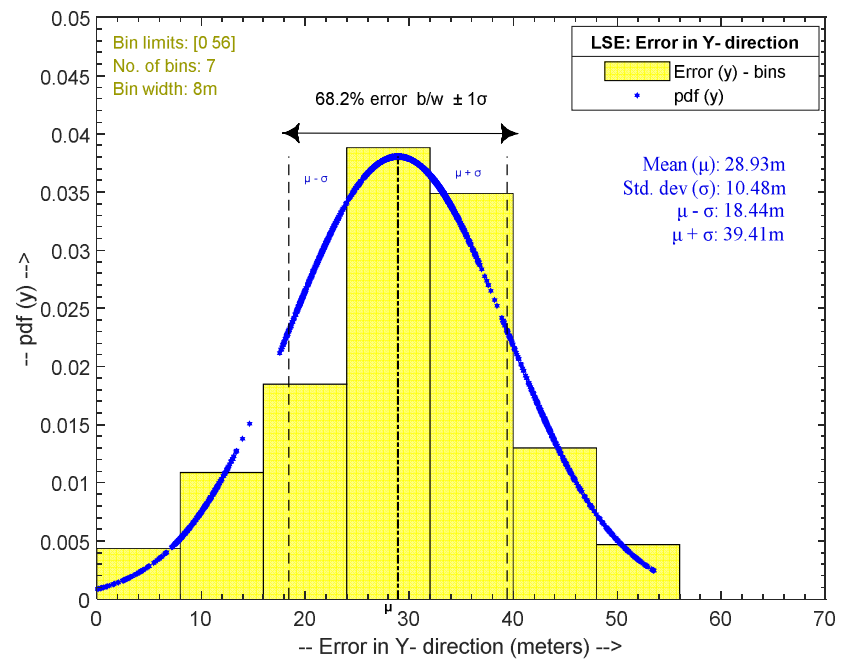

(a) Using LSE

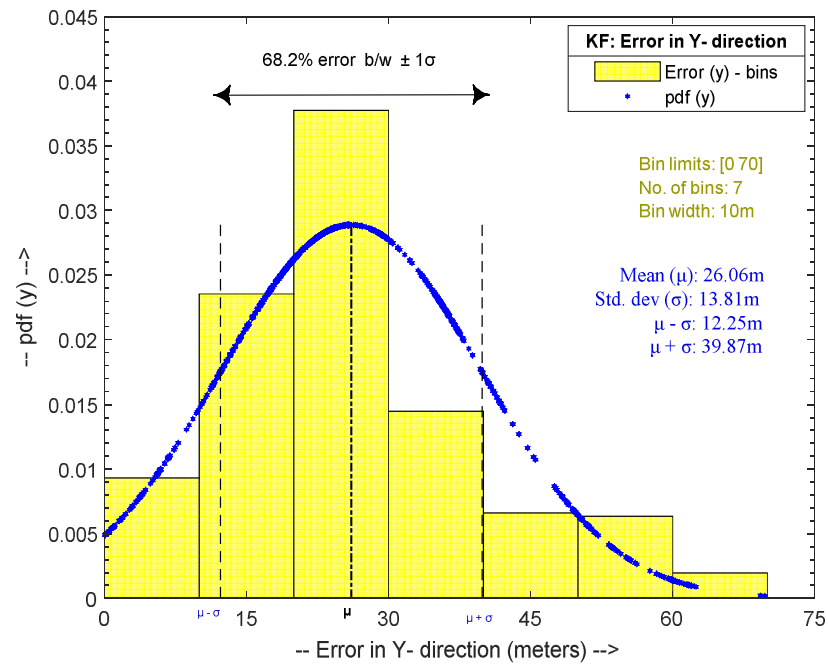

(b) Using KF

Fig. 8 Gaussian distribution of position error in 1-dimensional surface in Y-direction 


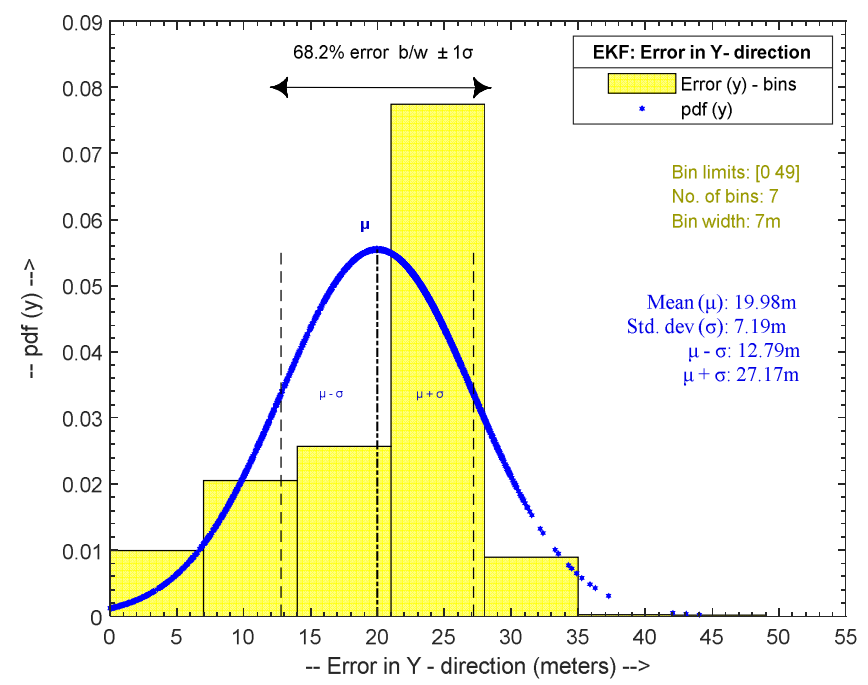

(c) Using EKF

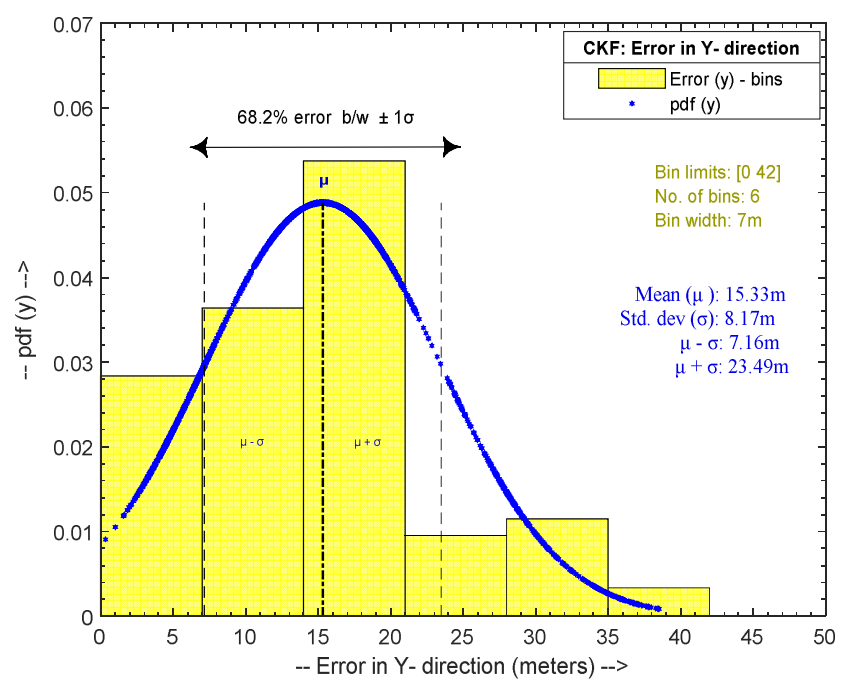

(d) Using CKF

Fig. 8 Gaussian distribution of position error in 1-dimensional surface in Y-direction (continued)

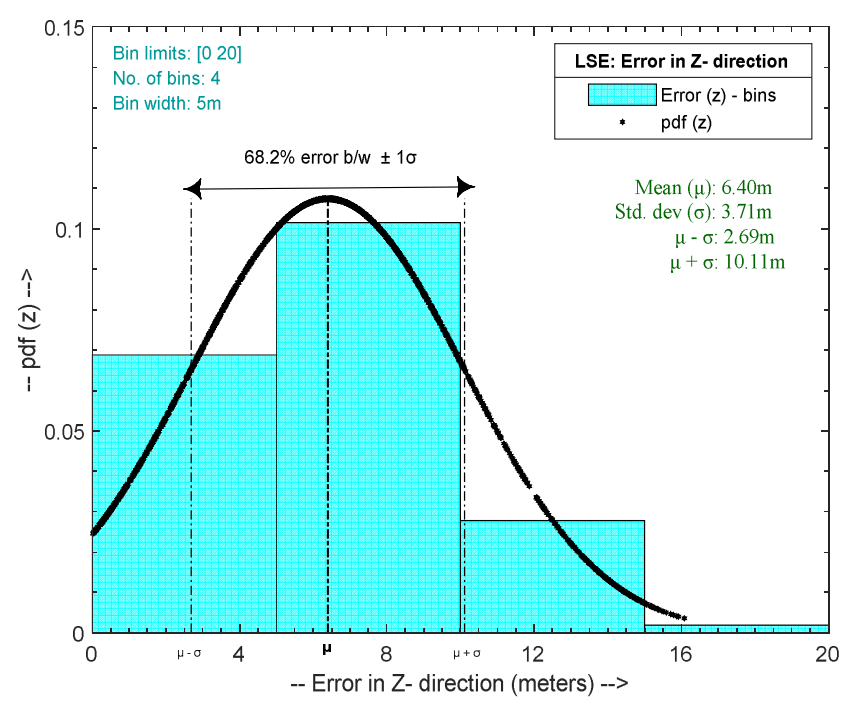

(a) Using LSE

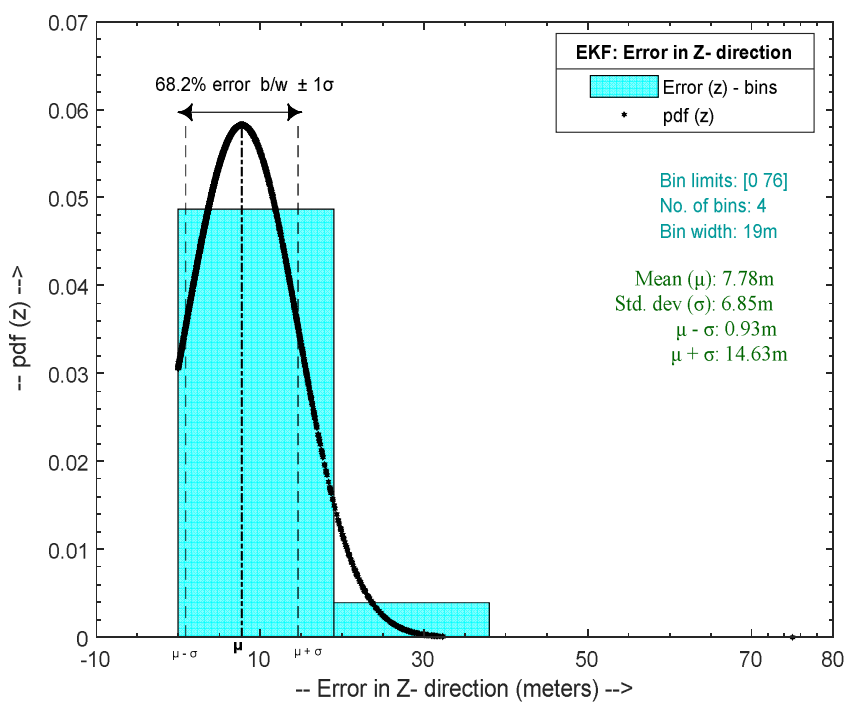

(c) Using EKF

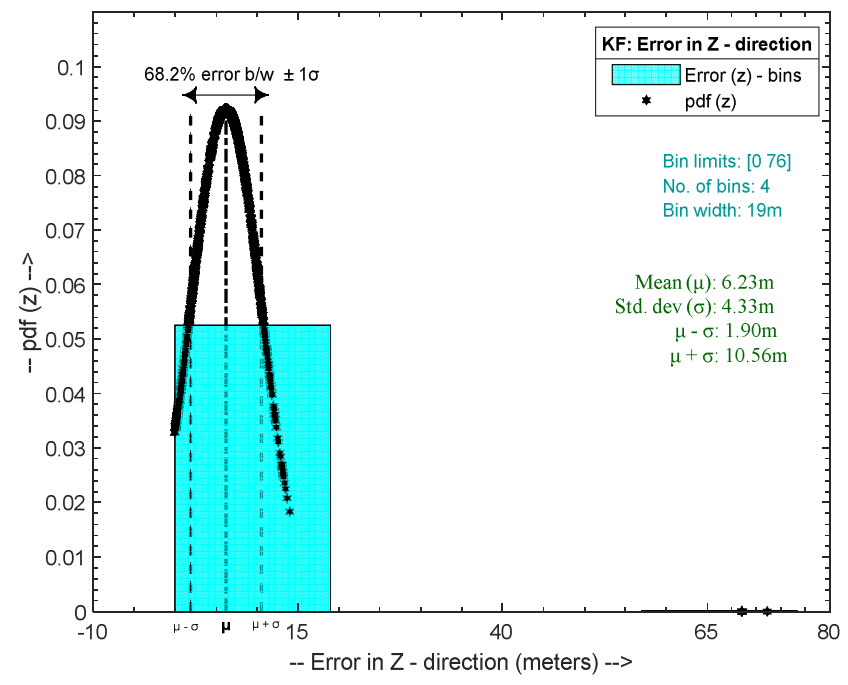

(b) Using KF

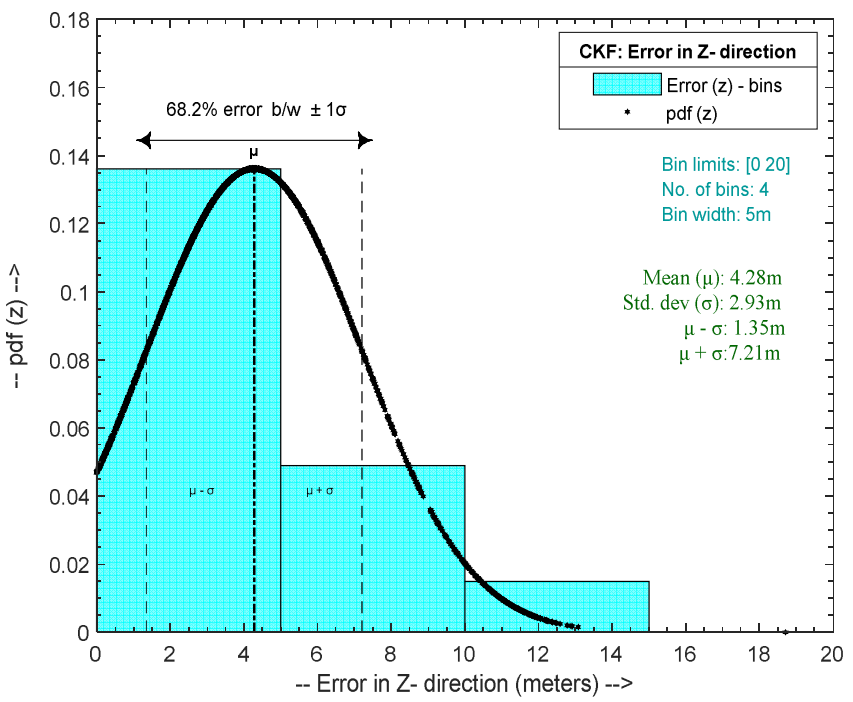

(d) Using CKF

Fig. 9 Gaussian distribution of position error in 1-dimensional surface in Z-direction 
Table 3 Statistical distribution of position error in X-direction

\begin{tabular}{|c|c|c|c|c|c|c|c|}
\hline \multicolumn{8}{|c|}{$\mathrm{X}$-direction } \\
\hline \multicolumn{2}{|r|}{ LSE } & \multicolumn{2}{|r|}{$\mathrm{KF}$} & \multicolumn{2}{|r|}{ EKF } & \multicolumn{2}{|r|}{$\mathrm{CKF}$} \\
\hline \multicolumn{2}{|c|}{ Bin limits: [18 67] } & \multicolumn{2}{|c|}{ Bin limits: [9 97] } & \multicolumn{2}{|c|}{ Bin limits: [0 42] } & \multicolumn{2}{|c|}{ Bin limits: [6 55] } \\
\hline \multicolumn{2}{|c|}{ No. of bins: 7} & \multicolumn{2}{|c|}{ No. of bins: 7} & \multicolumn{2}{|c|}{ No. of bins: 7} & \multicolumn{2}{|c|}{ No. of bins: 7} \\
\hline \multicolumn{2}{|c|}{ Bin width: $7 \mathrm{~m}$} & \multicolumn{2}{|c|}{ Bin width: $13 \mathrm{~m}$} & \multicolumn{2}{|c|}{ Bin width: $6 \mathrm{~m}$} & \multicolumn{2}{|c|}{ Bin width: $7 \mathrm{~m}$} \\
\hline $\begin{array}{l}\text { Bin edge } \\
\text { (meters) }\end{array}$ & No. of error points & $\begin{array}{l}\text { Bin edge } \\
\text { (meters) }\end{array}$ & No. of error points & $\begin{array}{l}\text { Bin edge } \\
\text { (meters) }\end{array}$ & No. of error points & $\begin{array}{l}\text { Bin edge } \\
\text { (meters) }\end{array}$ & No. of error points \\
\hline$\left[\begin{array}{ll}18 & 25\end{array}\right]$ & 181 & {$\left[\begin{array}{ll}10 & 23\end{array}\right]$} & 132 & {$\left[\begin{array}{ll}0 & 6\end{array}\right]$} & 96 & {$\left[\begin{array}{ll}6 & 13\end{array}\right]$} & 117 \\
\hline$\left[\begin{array}{ll}25 & 32\end{array}\right]$ & 813 & {$\left[\begin{array}{ll}23 & 36\end{array}\right]$} & 1379 & {$\left[\begin{array}{ll}6 & 12\end{array}\right]$} & 190 & {$\left[\begin{array}{ll}13 & 20\end{array}\right]$} & 593 \\
\hline [32 39] & 1011 & [36 49] & 971 & {$\left[\begin{array}{ll}12 & 18\end{array}\right]$} & 344 & {$\left[\begin{array}{ll}20 & 27\end{array}\right]$} & 1177 \\
\hline [39 46] & 465 & {$\left[\begin{array}{ll}49 & 62\end{array}\right]$} & 109 & [18 24] & 435 & [ $\left.\begin{array}{lll}27 & 34\end{array}\right]$ & 464 \\
\hline [46 53] & 128 & [62 75] & 4 & [24 30] & 925 & [34 41] & 247 \\
\hline [53 60] & 0 & {$\left[\begin{array}{lll}75 & 88\end{array}\right]$} & 0 & {$\left[\begin{array}{lll}30 & 36\end{array}\right]$} & 518 & [41 48] & 0 \\
\hline$\left[\begin{array}{ll}60 & 67\end{array}\right]$ & 1 & [88 101] & 7 & [36 42] & 91 & {$\left[\begin{array}{ll}48 & 55\end{array}\right]$} & 1 \\
\hline \multicolumn{2}{|c|}{$[2546] \rightarrow 88.1 \%$} & \multicolumn{2}{|c|}{$[23$ 49] $\rightarrow 90.4 \%$} & \multicolumn{2}{|c|}{$\left[\begin{array}{ll}18 & 36\end{array}\right] \rightarrow 72.3 \%$} & \multicolumn{2}{|c|}{$\left[\begin{array}{ll}13 & 34\end{array}\right] \rightarrow 86 \%$} \\
\hline \multicolumn{2}{|c|}{$\mathrm{X}_{\text {err_min }}: 18.19 \mathrm{~m}$} & \multicolumn{2}{|c|}{$\mathrm{X}_{\text {err_min }}: 16.66 \mathrm{~m}$} & \multicolumn{2}{|c|}{$\mathrm{X}_{\text {err_min }}: 0.24 \mathrm{~m}$} & \multicolumn{2}{|c|}{$\mathrm{X}_{\text {err_min }}: 8.19 \mathrm{~m}$} \\
\hline \multicolumn{2}{|c|}{$\mathrm{X}_{\text {err_max }}: 64.64 \mathrm{~m}$} & \multicolumn{2}{|c|}{$\mathrm{X}_{\text {err_max }}: 94.51 \mathrm{~m}$} & \multicolumn{2}{|c|}{$\mathrm{X}_{\text {err_max }}: 41.49 \mathrm{~m}$} & \multicolumn{2}{|c|}{$\mathrm{X}_{\text {err_max }}: 54.64 \mathrm{~m}$} \\
\hline
\end{tabular}

Table 4 Statistical distribution of position error in Y-direction

\begin{tabular}{|c|c|c|c|c|c|c|c|}
\hline \multicolumn{8}{|c|}{ Y-direction } \\
\hline \multicolumn{2}{|r|}{ LSE } & \multicolumn{2}{|r|}{$\mathrm{KF}$} & \multicolumn{2}{|r|}{ EKF } & \multicolumn{2}{|r|}{ CKF } \\
\hline \multicolumn{2}{|c|}{ Bin limits: [0 56] } & \multicolumn{2}{|c|}{ Bin limits: [0 70] } & \multicolumn{2}{|c|}{ Bin limits: [0 49] } & \multicolumn{2}{|c|}{ Bin limits: [0 42] } \\
\hline \multicolumn{2}{|c|}{ No. of bins: 7} & \multicolumn{2}{|c|}{ No. of bins: 7} & \multicolumn{2}{|c|}{ No. of bins: 7} & \multicolumn{2}{|c|}{ No. of bins: 6} \\
\hline \multicolumn{2}{|c|}{ Bin width: $8 \mathrm{~m}$} & \multicolumn{2}{|c|}{ Bin width: $10 \mathrm{~m}$} & \multicolumn{2}{|c|}{ Bin width: $7 \mathrm{~m}$} & \multicolumn{2}{|c|}{ Bin width: $7 \mathrm{~m}$} \\
\hline $\begin{array}{l}\text { Bin edge } \\
\text { (meters) }\end{array}$ & No. of error points & $\begin{array}{l}\text { Bin edge } \\
\text { (meters) }\end{array}$ & No. of error points & $\begin{array}{l}\text { Bin edge } \\
\text { (meters) }\end{array}$ & No. of error points & $\begin{array}{l}\text { Bin edge } \\
\text { (meters) }\end{array}$ & No. of error points \\
\hline$\left[\begin{array}{ll}0 & 8\end{array}\right]$ & 90 & [0 10] & 242 & {$\left[\begin{array}{ll}0 & 7\end{array}\right]$} & 181 & {$\left[\begin{array}{ll}0 & 7\end{array}\right]$} & 516 \\
\hline$\left[\begin{array}{ll}8 & 16\end{array}\right]$ & 226 & {$\left[\begin{array}{ll}10 & 20\end{array}\right]$} & 612 & {$\left[\begin{array}{ll}7 & 14\end{array}\right]$} & 373 & {$\left[\begin{array}{ll}7 & 14\end{array}\right]$} & 662 \\
\hline$\left[\begin{array}{ll}16 & 24\end{array}\right]$ & 384 & {$\left[\begin{array}{ll}20 & 30\end{array}\right]$} & 981 & [14 21] & 467 & {$\left[\begin{array}{ll}14 & 21\end{array}\right]$} & 978 \\
\hline$\left[\begin{array}{ll}24 & 32\end{array}\right]$ & 807 & {$\left[\begin{array}{lll}30 & 40\end{array}\right]$} & 376 & {$\left[\begin{array}{ll}21 & 28\end{array}\right]$} & 1409 & {$\left[\begin{array}{ll}21 & 28\end{array}\right]$} & 173 \\
\hline [32 40] & 725 & {$\left[\begin{array}{lll}40 & 50\end{array}\right]$} & 172 & {$\left[\begin{array}{ll}28 & 35\end{array}\right]$} & 162 & {$\left[\begin{array}{ll}28 & 35\end{array}\right]$} & 209 \\
\hline$\left[\begin{array}{ll}40 & 48\end{array}\right]$ & 270 & {$\left[\begin{array}{lll}50 & 60\end{array}\right]$} & 165 & [35 42] & 4 & {$\left[\begin{array}{ll}35 & 42\end{array}\right]$} & 61 \\
\hline$\left[\begin{array}{ll}48 & 56\end{array}\right]$ & 97 & {$\left[\begin{array}{ll}60 & 70] \\
\end{array}\right.$} & 51 & [42 49] & 3 & - & - \\
\hline \multicolumn{2}{|c|}{$[1640] \rightarrow 73.7 \%$} & \multicolumn{2}{|c|}{$[1040] \rightarrow 75.8 \%$} & \multicolumn{2}{|c|}{$\left[\begin{array}{l}728] \rightarrow 86.5 \% \\
\end{array}\right.$} & \multicolumn{2}{|c|}{$\left[\begin{array}{ll}0 & 21\end{array}\right] \rightarrow 83 \%$} \\
\hline \multicolumn{2}{|c|}{$\mathrm{Y}_{\text {err_min }}: 0.04 \mathrm{~m}$} & \multicolumn{2}{|c|}{$\mathrm{Y}_{\text {err_min }}: 0.05 \mathrm{~m}$} & \multicolumn{2}{|c|}{$\mathrm{Y}_{\text {err_min }}: 0.03 \mathrm{~m}$} & \multicolumn{2}{|c|}{$\mathrm{Y}_{\text {err_min }}: 0.34 \mathrm{~m}$} \\
\hline \multicolumn{2}{|c|}{$\mathrm{Y}_{\text {err_max }}: 53.51 \mathrm{~m}$} & \multicolumn{2}{|c|}{$Y_{\text {err_max }}: 69.75 \mathrm{~m}$} & \multicolumn{2}{|c|}{$\mathrm{Y}_{\text {err_max }}: 44.06 \mathrm{~m}$} & \multicolumn{2}{|c|}{$\mathrm{Y}_{\text {err_max }}: 38.51 \mathrm{~m}$} \\
\hline
\end{tabular}

Table 5 Statistical distribution of position error in Z-direction

\begin{tabular}{|c|c|c|c|c|c|c|c|}
\hline \multicolumn{8}{|c|}{ Z-direction } \\
\hline \multicolumn{2}{|r|}{ LSE } & \multicolumn{2}{|r|}{$\mathrm{KF}$} & \multicolumn{2}{|r|}{ EKF } & \multicolumn{2}{|r|}{$\mathrm{CKF}$} \\
\hline \multicolumn{2}{|c|}{ Bin limits: [ [ $\left.\begin{array}{ll}0 & 20\end{array}\right]$} & \multicolumn{2}{|c|}{ Bin limits: [0 76] } & \multicolumn{2}{|c|}{ Bin limits: [0 76] } & \multicolumn{2}{|c|}{ Bin limits: [ [ $\left.\begin{array}{ll}0 & 20\end{array}\right]$} \\
\hline \multicolumn{2}{|c|}{ No. of bins: 4} & \multicolumn{2}{|c|}{ No. of bins: 4} & \multicolumn{2}{|c|}{ No. of bins: 4} & \multicolumn{2}{|c|}{ No. of bins: 4} \\
\hline \multicolumn{2}{|c|}{ Bin width: $5 \mathrm{~m}$} & \multicolumn{2}{|c|}{ Bin width: $19 \mathrm{~m}$} & \multicolumn{2}{|c|}{ Bin width: $19 \mathrm{~m}$} & \multicolumn{2}{|c|}{ Bin width: $5 \mathrm{~m}$} \\
\hline $\begin{array}{c}\text { Bin edge } \\
\text { (meters) }\end{array}$ & No. of error points & $\begin{array}{l}\text { Bin edge } \\
\text { (meters) }\end{array}$ & No. of error points & $\begin{array}{l}\text { Bin edge } \\
\text { (meters) }\end{array}$ & No. of error points & $\begin{array}{c}\text { Bin edge } \\
\text { (meters) }\end{array}$ & No. of error points \\
\hline$\left[\begin{array}{ll}0 & 5\end{array}\right]$ & 894 & {$\left[\begin{array}{ll}0 & 19\end{array}\right]$} & 2594 & {$\left[\begin{array}{ll}0 & 19\end{array}\right]$} & 2404 & {$\left[\begin{array}{ll}0 & 5\end{array}\right]$} & 1768 \\
\hline$\left[\begin{array}{ll}5 & 10\end{array}\right]$ & 1320 & {$\left[\begin{array}{ll}19 & 38\end{array}\right]$} & 0 & [l 1938$]$ & 194 & {$\left[\begin{array}{ll}5 & 10\end{array}\right]$} & 636 \\
\hline$\left[\begin{array}{ll}10 & 15\end{array}\right]$ & 361 & [38 57] & 0 & [38 57] & 0 & {$\left[\begin{array}{ll}10 & 15\end{array}\right]$} & 194 \\
\hline$\left[\begin{array}{ll}15 & 20\end{array}\right]$ & 24 & [57 76] & 5 & [57 76] & 1 & {$\left[\begin{array}{ll}15 & 20\end{array}\right]$} & 1 \\
\hline \multicolumn{2}{|c|}{$\left[\begin{array}{ll}0 & 15\end{array}\right] \rightarrow 99.1 \%$} & \multicolumn{2}{|c|}{$\left[\begin{array}{ll}0 & 19\end{array}\right] \rightarrow 99.8 \%$} & \multicolumn{2}{|c|}{$\left[\begin{array}{ll}0 & 19\end{array}\right] \rightarrow 92.5 \%$} & \multicolumn{2}{|c|}{$\left[\begin{array}{ll}0 & 10\end{array}\right] \rightarrow 92.5 \%$} \\
\hline \multicolumn{2}{|c|}{$\mathrm{Z}_{\mathrm{err} \_\min }: 0.02 \mathrm{~m}$} & \multicolumn{2}{|c|}{$\mathrm{Z}_{\mathrm{err} \_\min }: 0.01 \mathrm{~m}$} & \multicolumn{2}{|c|}{$\mathrm{Z}_{\text {err_min }}: 0.0 \mathrm{~m}$} & \multicolumn{2}{|c|}{$Z_{\text {err_min }}: 0.0 \mathrm{~m}$} \\
\hline \multicolumn{2}{|c|}{$\mathrm{Z}_{\text {err_max }}: 16.08 \mathrm{~m}$} & \multicolumn{2}{|c|}{$\mathrm{Z}_{\text {err_max }}: 72.33 \mathrm{~m}$} & \multicolumn{2}{|c|}{$\mathrm{Z}_{\mathrm{err} \_\max }: 75.0 \mathrm{~m}$} & \multicolumn{2}{|c|}{$\mathrm{Z}_{\mathrm{err} \_\max }: 18.71 \mathrm{~m}$} \\
\hline
\end{tabular}

\subsection{Statistical error characterization in 2-dimensional surface}

The obtained statistical position accuracy metrics in 2-dimensional surface due to the four algorithms are provided in Table 6 [31-32]. Furthermore, Fig. 10 compares the horizontal position error (X and Y) scatter plot with circular error probable (CEP) among the four algorithms. It is evident that from Fig. 10, the CEP circle (red color solid line circle) due to the CKF algorithm is miniature and seems closer to the origin than the other three algorithms (LSE, KF, and EKF). 
Table 6 Comparison of statistical position accuracy measures among four algorithms in 2-dimensional surface

\begin{tabular}{|c|c|c|c|c|c|c|}
\hline \multirow{2}{*}{ Statistical position accuracy measure (SAM) } & \multirow{2}{*}{ Probability } & \multirow{2}{*}{ Formula } & \multicolumn{4}{|c|}{ (In meters) } \\
\hline & & & LSE & $\mathrm{KF}$ & EKF & CKF \\
\hline Distance root mean square (DRMS) & $65 \%$ & $\sqrt{\sigma_{x}^{2}+\sigma_{y}^{2}}$ & 12.39 & 15.83 & 10.97 & 10.46 \\
\hline Twice distance root mean square (2DRMS) & $95-98 \%$ & $2 \sqrt{\sigma_{\mathrm{x}}^{2}+\sigma_{\mathrm{y}}^{2}}$ & 24.78 & 31.66 & 21.93 & 20.93 \\
\hline Circular error probable (CEP) & $50 \%$ & $\begin{array}{c}0.62 \sigma_{x}+0.56 \sigma_{y} \\
\left(\text { accurate when } \sigma_{y} / \sigma_{x}>0.3\right)\end{array}$ & 10.20 & 12.90 & 9.09 & 8.73 \\
\hline Horizontal 95 percent accuracy (R95) & $95 \%$ & $\begin{array}{c}2.08\left(0.62 \sigma_{\mathrm{x}}+0.56 \sigma_{\mathrm{y}}\right) \\
\left(\mathrm{R}=2.08, \text { when } \sigma_{\mathrm{y}} / \sigma_{\mathrm{x}} \geq 1\right)\end{array}$ & 21.21 & 26.82 & 18.92 & 18.15 \\
\hline
\end{tabular}

Note: The statistical position accuracy measures are calculated for the entire data range after neglecting other correctable error sources.

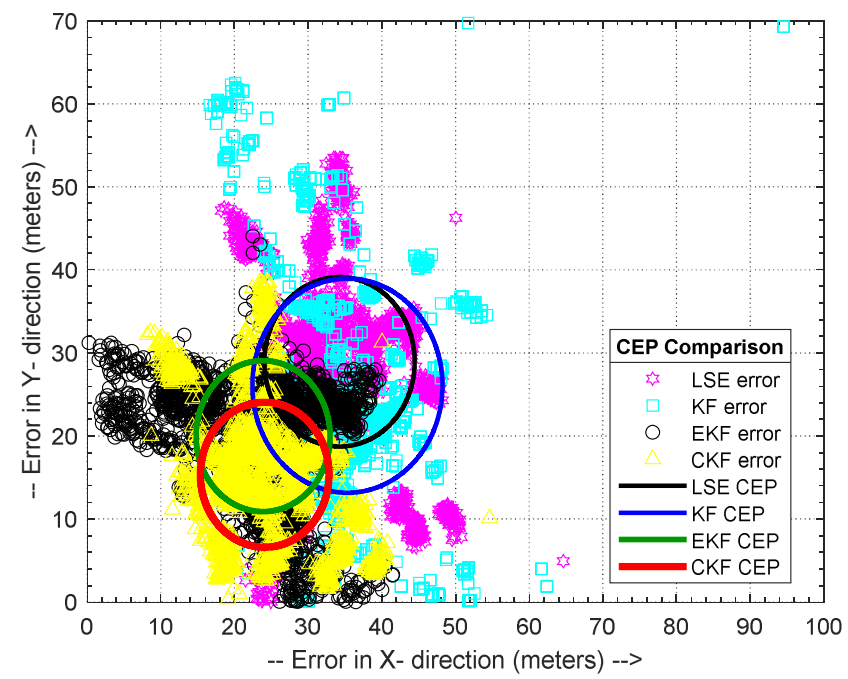

Fig. 10 Horizontal position error scatter plot with CEP among four algorithms

\subsection{Statistical error characterization in 3-dimensional surface}

Similarly, the obtained position accuracy metrics in 3-dimensional surface due to the four algorithms are provided in Table 7 [31-32]. Furthermore, Fig. 11 compares the horizontal and vertical position error (X, Y, and Z) scatter plot in 3-dimensional surface with spherical error probable (SEP) among the four algorithms.

It is evident that from Fig. 11, the SEP sphere (red color sphere) due to the CKF algorithm is miniature and seems closer to the origin than the other three algorithms (LSE, KF, and EKF). Besides, the positioning simulation results are compared with the reference algorithms [26, 30,33] in terms of accuracy and computational time. CKF itself has far better computational time than the firefly algorithm (FA), teaching learning based optimization (TLBO), KF, and EKF. The computational time reported is $50.38 \mathrm{sec}$ for FA, $3.13 \mathrm{sec}$ for TLBO, $5.85 \mathrm{sec}$ for EKF, $6.80 \mathrm{sec}$ for KF, and $2.290 \mathrm{sec}$ for CKF. Also, with the computational time, the mean values are presented in Table 8 . The simulation results indicate that the proposed method has the best performance in speed and accuracy generally, as compared to FA, TLBO, KF, and EKF methods, respectively.

It has been stated that from the above figures and tabular forms, the proposed CKF algorithm can provide a highly precise and accurate position estimation contrasted to the other three algorithms (LSE, KF, and EKF). Therefore, the overall observations summarize that the GPS receiver position estimation accuracy is significantly improved when using the proposed algorithm, i.e., the CKF algorithm. Hence, the CKF algorithm can estimate the GPS receiver position in the Indian subcontinent's southern region. 
Table 7 Comparison of statistical position accuracy measures among four algorithms in 3-dimensional surface

\begin{tabular}{|c|c|c|c|c|c|c|}
\hline Statistical position accuracy measure (SAM) & \multirow{2}{*}{ Probability } & Formula & \multicolumn{3}{|c|}{ (In meters) } \\
\cline { 4 - 7 } & & LSE & KF & EKF & CKF \\
\hline Spherical error probable (SEP) & $50 \%$ & $0.51\left(\sigma_{\mathrm{x}}+\sigma_{\mathrm{y}}+\sigma_{\mathrm{z}}\right)$ & 10.61 & 13.20 & 11.38 & 9.00 \\
\hline Mean radial spherical error (MRSE) & $61 \%$ & $\sqrt{\sigma_{\mathrm{x}}^{2}+\sigma_{\mathrm{y}}^{2}+\sigma_{z}^{2}}$ & 12.94 & 16.41 & 12.93 & 10.87 \\
\hline $90 \%$ spherical accuracy standard (SAS_90\%) & $90 \%$ & $0.833\left(\sigma_{\mathrm{x}}+\sigma_{\mathrm{y}}+\sigma_{\mathrm{z}}\right)$ & 17.33 & 21.56 & 18.59 & 14.69 \\
\hline $99 \%$ spherical accuracy standard (SAS_99\%) & $99 \%$ & $1.122\left(\sigma_{\mathrm{x}}+\sigma_{\mathrm{y}}+\sigma_{\mathrm{z}}\right)$ & 23.34 & 29.04 & 25.04 & 19.79 \\
\hline
\end{tabular}

Note: The statistical position accuracy measures are calculated for the entire data range after neglecting other correctable error sources.

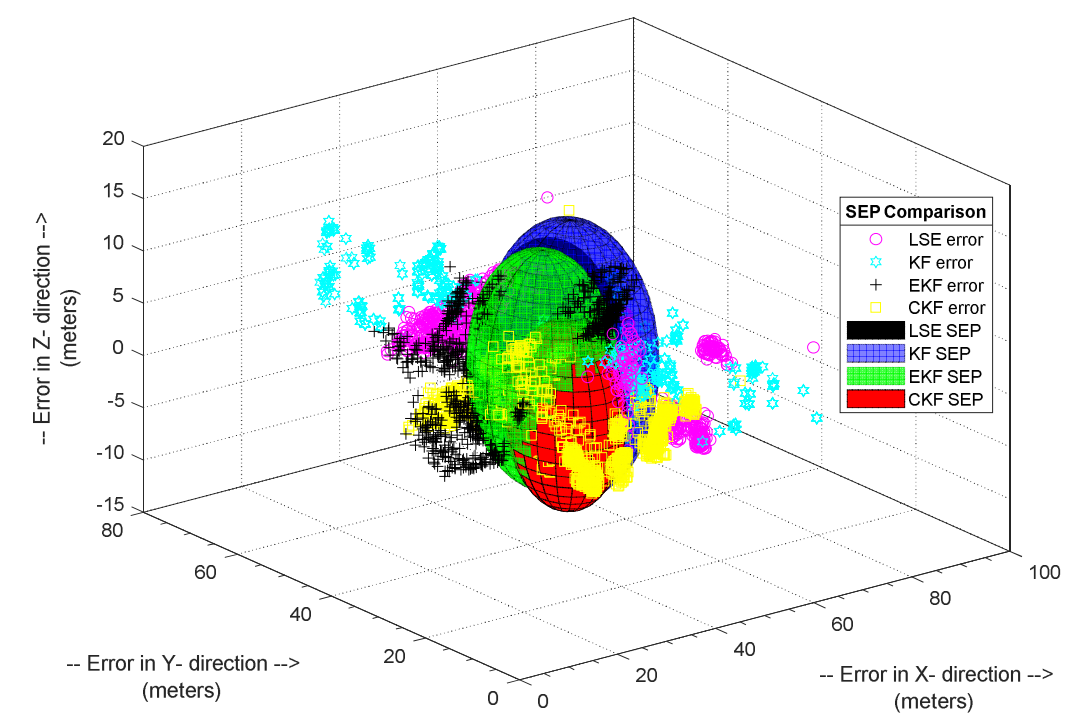

Fig. 11 3-dimensional position error scatter plot with SEP among four algorithms

Table 8 Comparison of mean error and computational time

\begin{tabular}{|c|c|c|c|c|}
\hline \multirow{2}{*}{ Algorithm } & \multirow{2}{*}{ Computational time (seconds) } & \multicolumn{3}{|c|}{ Mean error (meters) } \\
\cline { 3 - 5 } & & $\mathrm{X}$ & $\mathrm{Y}$ & $\mathrm{Z}$ \\
\hline Firefly algorithm (FA) [33] & 50.38 & 50.00 & 132.00 & 41.80 \\
\hline Teaching learning based optimization (TLBO) [33] & 3.13 & 52.52 & 133.99 & 45.78 \\
\hline Extended Kalman filter (EKF) [30] & 6.80 & 35.33 & 26.06 & 6.23 \\
\hline Kalman filter (KF) [26] & 5.85 & 48.47 & 100.63 & 34.60 \\
\hline Correntropy Kalman filter (CKF) & 2.30 & 24.01 & 15.52 & 3.90 \\
\hline
\end{tabular}

\section{Conclusions}

The minimum requirement of four satellite visibility in GPS does not prevail every time, and the visibility is remarkably low in urban canyons and places with high raised buildings. Therefore, the CKF algorithm is developed, and the performance is compared with the other three algorithms (LSE, KF, and EKF). Also, the position error mean and variance due to the CKF algorithm are observed to be minimum and better over the LSE, KF, and EKF algorithms. The values of statistical position accuracy measures are also less for the $\mathrm{CKF}$ algorithm than the other three algorithms. Hence, with due consideration of all correctable errors, it is concluded that the proposed CKF algorithm provides a significant improvement in position accuracy and helps achieve the accuracy requirement of GAGAN users, CAT-1 aircraft landings, and other GPS-based navigation applications over the low latitude Indian subcontinent.

\section{Conflicts of Interest}

The authors declare no conflict of interest. 


\section{References}

[1] D. H. Ji, H. S. Choi, S. K. Jeong, J. Y. Oh, S. K. Kim, and S. S. You, “A Study on Heading and Attitude Estimation of Underwater Track Vehicle,” Advances in Technology Innovation, vol. 4, no. 2, pp. 84-93, April 2019.

[2] M. Allahyari, M. J. Olsen, D. T. Gillins, and M. L. Dennis, "Evaluation of the Horizontal and Vertical Accuracy of GNSS Survey Observations from a Real-Time Network," AGU Fall Meeting Abstracts, vol. 2016, pp. G21B-1003, December 2016.

[3] International Civil Aviation Organization, "Manual on Required Navigation Performance (RNP)," Montreal: International Civil Aviation Organization, 1999.

[4] H. Xiong, J. Tang, H. Xu, W. Zhang, and Z. Du, “A Robust Single GPS Navigation and Positioning Algorithm Based on Strong Tracking Filtering,” IEEE Sensors Journal, vol. 18, no. 1, pp. 290-298, January 2018.

[5] X. Wang and M. Liang, "GPS Positioning Method Based on Kalman Filtering," International Conference on Robots and Intelligent System, May 2018, pp. 77-80.

[6] G. L. Jia, N. Li, M. M. Bai, and Y. G. Zhang, "A Novel Student's t-based Kalman Filter with Colored Measurement Noise," Circuits, Systems, and Signal Processing, vol. 39, no. 8, pp. 4225-4242, August 2020.

[7] Y. Huang and Y. Zhang, "A New Process Uncertainty Robust Student's t Based Kalman Filter for SINS/GPS Integration," IEEE Access, vol. 5, pp. 14391-14404, 2017.

[8] A. Santra, S. Mahato, S. Dan, and A. Bose, "Precision of Satellite Based Navigation Position Solution: A Review Using NavIC Data,” Journal of Information and Optimization Sciences, vol. 40, no. 8, pp. 1683-1691, 2019.

[9] C. Rajasekhar, V. B. S. S. I. Dutt, and G. S. Rao, "Weighted GDoP for Improved Position Accuracy Using NavIC and GPS Hybrid Constellation over Indian Sub-Continent," International Journal of Intelligent Networks, vol. 2, pp. 42-45, 2021.

[10] H. Hatano, T. Kitani, M. Fujii, Y. Watanabe, and H. Onishi, "A Helpful Positioning Method with Two GNSS Satellites in Urban Area," 3rd International Conference on Mobile Services, Resources, and Users, pp. 41-46, November 2013.

[11] M. I. Ribeiro, "Kalman and Extended Kalman Filters: Concept, Derivation and Properties," Institute for Systems and Robotics, Technical Report, February 2004.

[12] M. Eliasson, “A Kalman Filter Approach to Reduce Position Error for Pedestrian Applications in Areas of Bad GPS Reception,” Degree Project, Bachelor's Programme in Computing Science, UMEA University, 2014.

[13] C. Luo, S. I. McClean, G. Parr, L. Teacy, and R. De Nardi, "UAV Position Estimation and Collision Avoidance Using the Extended Kalman Filter,” IEEE Transactions on Vehicular Technology, vol. 62, no. 6, pp. 2749-2762, July 2013.

[14] S. Shokri, N. Rahemi, and M. R. Mosavi, "Improving GPS Positioning Accuracy Using Weighted Kalman Filter and Variance Estimation Methods,” CEAS Aeronautical Journal, vol. 11, no. 2, pp. 515-527, June 2020.

[15] Y. Hao, A. Xu, X. Sui, and Y. Wang, “A Modified Extended Kalman Filter for a Two-Antenna GPS/INS Vehicular Navigation System,” Sensors, vol. 18, no. 11, 3809, November 2018.

[16] D. J. Jwo and T. S. Cho, "Critical Remarks on the Linearised and Extended Kalman Filters with Geodetic Navigation Examples," Measurement, vol. 43, no. 9, pp. 1077-1089, November 2010.

[17] Q. Ge, T. Shao, S. Chen, and C. Wen, "Carrier Tracking Estimation Analysis by Using the Extended Strong Tracking Filtering," IEEE Transactions on Industrial Electronics, vol. 64, no. 2, pp. 1415-1424, February 2017.

[18] Y. Zhang, C. Shen, J. Tang, and J. Liu, "Hybrid Algorithm Based on MDF-CKF and RF for GPS/INS System during GPS Outages,” IEEE Access, vol. 6, pp. 35343-35354, April 2018.

[19] Y. Zhang, J. Wang, Q. Sun, and W. Gao, “Adaptive Cubature Kalman Filter Based on the Variance-Covariance Components Estimation,” The Journal of Global Positioning Systems, vol. 15, no. 1, pp. 1-9, December 2017.

[20] X. Liu, B. Chen, H. Zhao, J. Qin, and J. Cao, “Maximum Correntropy Kalman Filter with State Constraints,” IEEE Access, vol. 5, pp. 25846-25853, 2017.

[21] W. Liu, P. P. Pokharel, and J. C. Principe, "Correntropy: Properties and Applications in Non-Gaussian Signal Processing," IEEE Transactions on Signal Processing, vol. 55, no. 11, pp. 5286-5298, November 2007.

[22] W. Liu, P. P. Pokharel, and J. C. Principe, “Correntropy: A Localized Similarity Measure,” IEEE International Joint Conference on Neural Network Proceedings, pp. 4919-4924, July 2006.

[23] B. Chen, L. Xing, J. Liang, N. Zheng, and J. C. Principe, "Steady-State Mean-Square Error Analysis for Adaptive Filtering under the Maximum Correntropy Criterion,” IEEE Signal Processing Letters, vol. 21, no.7, pp. 880-884, July 2014.

[24] J. C. Principe, D. Xu, Q. Zhao, and J. W. Fisher, "Learning from Examples with Information Theoretic Criteria,” Journal of VLSI Signal Processing Systems for Signal, Image, and Video Technology, vol. 26, no. 1, pp. 61-77, August 2000.

[25] M. S. Grewal and A. P. Andrews, "Kalman Filtering: Theory and Practice Using MATLAB", 4th ed., New York: Wiley, 2015 . 
[26] P. S. Kumar and V. B. S. S. I. Dutt, "Navigation Solutions for GPS Receiver Position Estimation over the Southern Region of India,” International Journal of Recent Technology and Engineering, vol. 7, no. 6, pp. 1672-1675, March 2019.

[27] X. Liu, H. Qu, J. Zhao, and B. Chen, "Extended Kalman Filter under Maximum Correntropy Criterion,” International Joint Conference on Neural Networks, pp. 1733-1737, July 2016.

[28] P. S. Kumar, V. B. S. S. I. Dutt, and G. Laveti, “A Novel Kinematic Positioning Algorithm for GPS Applications in Urban Canyons,” Materials Today: Proceedings, vol. 33, pp. 3359-3365, 2020.

[29] B. Chen, X. Liu, H. Zhao, and J. C. Principe, “Maximum Correntropy Kalman Filter,” Automatica, vol. 76, pp. 70-77, February 2017.

[30] N. A. Kumar, C. Suresh, and G. S. Rao, "Extended Kalman Filter for GPS Receiver Position Estimation,” International Conference on Frontiers of Intelligent Computing: Theory and Applications, pp. 481-488, November 2018.

[31] NovAtel, "Statistics and Its Relationship to Accuracy Measure in GPS," https://www.mat.uc.pt/ gil/downloads/GPSMedidasExactidao.pdf, December 03, 2003.

[32] F. van Diggelen, “GNSS Accuracy: Lies, Damn Lies, and Statistics,” GPS World, vol. 18, no. 1, pp. $26-32$, January 2007.

[33] L. Bagadi, G. S. Rao, and N. A. Kumar, "Firefly, Teaching Learning Based Optimization and Kalman Filter Methods for GPS Receiver Position Estimation,” Procedia Computer Science, vol. 143, pp. 892-898, 2018.

Copyright $\bigcirc$ by the authors. Licensee TAETI, Taiwan. This article is an open access article distributed under the terms and conditions of the Creative Commons Attribution (CC BY-NC) license (https://creativecommons.org/licenses/by-nc/4.0/). 